\title{
LESSONS ON ENGAGING WITH THE PRIVATE SECTOR TO STRENGTHEN CLIMATE RESILIENGE IN GUATEMALA, THE PHILIPPINES AND SENEGAL
}

Juan Casado-Asensio, Takayoshi Kato and Heiwon Shin
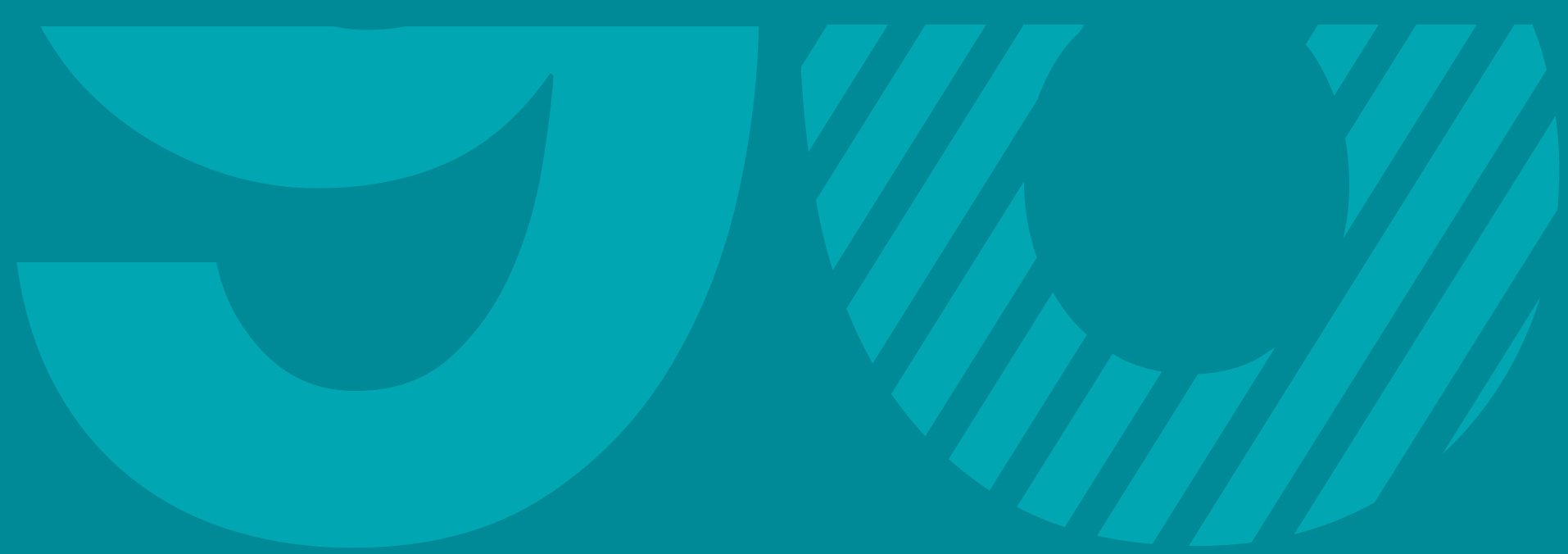

\section{OECD DEVELOPMENT CO-OPERATION WORKING PAPER 96}

Authorised for publication by Jorge Moreira da Silva, Director, Development Co-operation Directorate 

OECD Working Papers do not represent the official views of the OECD or of its member countries. The opinions expressed and arguments employed are those of the authors. Working Papers describe preliminary results or research in progress by the authors and are published to stimulate discussion on a broad range of issues on which the OECD works. Comments on this Working Paper are welcome and may be sent to dac.contact@oecd.org - Development Co-ordination Directorate, OECD, 2 rue André Pascal, 75775 Paris Cedex 16, France.

This document, as well as any data and any map included herein, are without prejudice to the status of or sovereignty over any territory, to the delimitation of international frontiers and boundaries and to the name of any territory, city or area.

Please cite this paper as Casado-Asensio, J., Kato, T. and Shin, H. (2021), Lessons on engaging with the private sector to strengthen climate resilience in Guatemala, the Philippines and Senegal, OECD Development Co-operation Working Paper no. 96, OECD Publishing, Paris. 


\section{Abstract}

Many private sector actors already see the increasing impacts of climate change as a major threat to their businesses. Yet, these actors, especially micro, small and medium-sized enterprises (MSMEs) are struggling to understand how the impacts of climate change may influence their business profitability and continuity over time, and how they can manage climate risks. Significant gaps in individual, institutional and systemic capacity, available resources, and data and information continue to constrain developing countries' efforts to strengthen the resilience of the private sector to climate-related hazards.

This working paper explores how governments and development co-operation providers can further engage with the private sector to address these constraints and strengthen its resilience to the negative impacts of climate change. The paper focuses on different roles of the private sector in strengthening climate resilience. It then examines how governments and development co-operation can foster such roles through enhancing domestic institutions and networks, policy frameworks, climate and weather data and information, and financing mechanisms. The proposed actions draw from the experiences of three case studies: Guatemala, the Philippines and Senegal. 


\section{Foreword}

Lessons on engaging with the private sector to strengthen climate resilience in Guatemala, the Philippines and Senegal is a product of the OECD Development Co-operation Directorate, drafted by Juan CasadoAsensio, Takayoshi Kato and Heiwon Shin, under the guidance of Jens Sedemund. This working paper has informed the development of the OECD report, Strengthening Climate Resilience, developed under the Development Assistance Committee (DAC) and the Environment Policy Committee of the OECD (https://oe.cd/climate-resilience).

The authors are grateful for the valuable comments and input provided by members of DAC Network for Environment and Development (ENVIRONET). The report also greatly benefited from the inputs of various officials of the case study countries, including Juan Carlos Diaz Contreras (Ministry of Environment and Natural Resources), Ousmane Fall Sarr (National Committee on Climate Change), Remedios SorianoEndencia (National Economic and Development Authority of the Philippines) and their teams.

The authors would also like to thank OECD colleagues for their review and input throughout the process: Haje Schütte, Nicolina Lamhauge and Shashwati Shankar Padmanabhan. The production benefited from the assistance of Sabrina Bouldi, Stacey Bradbury, Sara Casadevall Bellés, Samantha Proteau and Jessica Voorhees.

The authors are grateful for the financial contribution by the Deutsche Gesellschaft für Internationale Zusammenarbeit $\mathrm{GmbH}(\mathrm{GIZ})$ by the Global Programme on Risk Assessment and Management for Adaptation to Climate Change (Loss and Damage) as well as the support provided by GIZ colleagues: Michael Siebert, Ivo Litzenberg, Björn Surborg, Maria Teresa Escamilla Bran and Ezgi Basar in the implementation of the project. 


\section{Table of contents}

$\begin{array}{ll}\text { Abstract } & 4\end{array}$

Foreword 5

$\begin{array}{ll}\text { Abbreviations and acronyms } & 7\end{array}$

Executive summary $\quad 8$

1. Approaches to engaging the private sector in strengthening climate resilience $\quad 10$

1.1. Strengthening climate resilience of the private sector for sustainable development 11

1.2. Need for greater engagement with the private sector 12

1.3. Motivation and challenges for the private sector to act on climate resilience 14

1.4. Varying roles of the private sector in strengthening climate resilience 15

1.5. Ways forward to enhance private sector engagement in building climate resilience 20

2. Summaries of the case studies on Guatemala, the Philippines and Senegal 35

2.1. Approaches in Guatemala: Findings and ways forward 36

2.2. Approaches in the Philippines: Findings and ways forward $\quad 41$

2.3. Approaches in Senegal: Findings and ways forward 46

References $\quad 51$

\section{Tables}

Table 1. Checklist for action by governments and development co-operation 9

Table 1.1. A typology of private sector actors and their roles in action on climate resilience 16

Table 1.2. Key aspects for greater engagement with the private sector in climate resilience building 20

Table 1.3. Examples of financial instruments in support of climate resilience in the Philippines 32

\section{Boxes}

$\begin{array}{lr}\text { Box 1.1. Concepts of climate resilience } & 12\end{array}$

Box 1.2. Case studies on Guatemala, the Philippines and Senegal 13

Box 1.3. Definition of MSMEs $\quad 14$

Box 1.4. Private-sector initiatives in providing climate and weather data and information in Guatemala 18

Box 1.5. Examples of business associations and their networks for strengthening climate resilience 23

Box 1.6. Co-ordination mechanisms for coherent development co-operation efforts 25

Box 1.7. Further examples of development co-operation enabling policies on climate resilience 28

Box 1.8. Tools in support of MSMEs' decision making on climate resilience 30

Box 1.9. Greening financial systems in the Philippines $\quad 33$

Box 1.10. Legal barriers to entrance of private sector companies to the insurance market 34 


\section{Abbreviations and acronyms}

ADB

ANACIM

ARISE

CNAAS

COMNACC

COMRECC

CSR

DRRM

GDP

GIZ

ICC

INSIVUMEH

LGU

MiCRO

MSME

NEDA

OECD

PAGASA

PAP

$\mathrm{PCCl}$

PCIC

PIRA

PSE

SB Corp
Asian Development Bank

National Agency for Civil Aviation and Meteorology

Private Sector Alliance for Disaster Resilient Societies

Compagnie Nationale d'Assurance Agricole du Sénégal

National Committee of Climate Change of Senegal

Regional Committee of Climate Change of Senegal

Corporate social responsibility

Disaster risk reduction and management

Gross domestic product

Deutsche Gesellschaft für Internationale Zusammenarbeit (German Corporation for International Cooperation)

Institute for Climate Change Research

National Institute for Seismology Volcanology, Meteorology and Hydrology of Guatemala

Local government unit

Microinsurance Catastrophe Risk Organization

Micro, small and medium-sized enterprises

National Economic Development Authority

Organisation for Economic Co-operation and Development

National Agency for Civil Aviation and Meteorology

Plan d'Actions Prioritaires (Priority action plan)

Philippine Chamber of Commerce and Industry

Philippine Crop Insurance Corporation

Philippines Insurers and Reinsurers Association

Plan Sénégal Émergent (Plan for an Emerging Senegal)

Small Business Corporation 


\section{Executive summary}

Strengthening climate resilience of the private sector, especially micro, small and medium-sized enterprises (MSMEs), is an integral part of countries' efforts towards sustainable development. In Guatemala, the Philippines and Senegal (henceforth, the case study countries), MSMEs make significant contributions to the economy and employment. MSMEs also tend to be particularly vulnerable to external shocks, including climate hazards and economic impacts of the COVID-19 pandemic. Private sector actors have been increasingly engaged in efforts to strengthen MSMEs' climate resilience. Uncertainties and complexity presented by climate change however make it harder for MSMEs to understand its possible impacts on their business profitability and continuity, and approaches they can take to manage climate risks over time.

Governments and development co-operation providers have already been working to address the barriers that hinder MSMEs' action on climate resilience. Their role spans a range of areas, from developing and implementing policies that incentivise MSMEs to manage climate risks on their business, to facilitating collaboration and partnerships among the public and private sectors, as well as research institutes and other non-state actors. Governments, often with support from development co-operation, also provide public goods, such as weather and climate information and critical infrastructure.

Many institutions and initiatives have been established to support various development agendas such as climate action, disaster risk reduction and MSME development in the case study countries. Greater co-ordination among these institutions and initiatives can directly or indirectly promote the governments' efforts to enhance MSMEs' climate resilience in an efficient way. In the case study countries, the governments, the private sector and development partners, or their networks, have been supporting those thematic initiatives to a varying extent. Yet, coherent implementation of approaches between climate resilience and the different policy agendas remains a challenge. Policy coherence is now more important than ever for the case study countries facing the compounded impacts of both the COVID-19 pandemic and the emerging negative impacts of climate change on their economies.

Greater efforts are needed to reduce administrative burdens and create incentives for MSMEs' participation in policy dialogues on climate resilience, and sustain the engagement. Furthermore, a significant portion of MSMEs operate in the informal sector. They are often left outside such engagement processes, and have limited access to policy support and opportunities for information exchange, despite their immediate need for technical and financial support in building climate resilience.

A greater level of financial and technical support by development co-operation in data and information can help MSMEs better understand climate risks. Reliable and legitimate weather and climate data and information are essential for supporting policy and financial decision making on MSMEs' climate resilience. While some private sector actors in the case study countries have been producing such data and information, those initiatives are in many cases taken as corporate social responsibility activities or as a means to protect a particular value chain. It appears challenging even for large companies to scale up or sustain such initiatives as a revenue-generating business model. 
To tackle these challenges and seize opportunities to enhance climate resilience of MSMEs, the table below provides the governments and development co-operation with recommended actions in the form of a checklist. The proposed actions draw from the experiences of the three case studies, but may also provide insights to a broader range of countries and their development co-operation partners.

\section{Table 1. Checklist for action by governments and development co-operation}

\begin{tabular}{|c|c|c|}
\hline & ACTIONS ${ }^{1}$ & $\operatorname{ACTOR}(\mathbf{S})^{2}$ \\
\hline \multicolumn{3}{|c|}{ Institutional arrangements and networks for climate resilience of MSMEs } \\
\hline & $\begin{array}{l}\text { Identify the most vulnerable private-sector actors (e.g. subsistence farmers, women-led small businesses, } \\
\text { fisherfolks in remote islands) and engage them in efforts to enhance MSMEs' climate resilience. }\end{array}$ & $\begin{array}{l}\text { Governments and } \\
\text { dev-co }\end{array}$ \\
\hline & $\begin{array}{l}\text { Deepen collaboration with business associations, or other private-sector networks, to set a common vision on } \\
\text { priority actions for climate resilience of MSMEs, and facilitate co-ordination and learning among actors, as well } \\
\text { as their access to technical and financial support. }\end{array}$ & $\begin{array}{l}\text { Governments and } \\
\text { dev-co }\end{array}$ \\
\hline & $\begin{array}{l}\text { Review and adjust the processes for MSMEs and their representatives, especially women, to participate in policy } \\
\text { dialogues on climate resilience. }\end{array}$ & $\begin{array}{l}\text { Governments with } \\
\text { support of dev-co }\end{array}$ \\
\hline \multicolumn{3}{|c|}{ Enabling policies for private sector engagement in climate resilience } \\
\hline & Explicitly consider issues of climate resilience of MSMEs in national, local and sectoral development policies. & Governments \\
\hline & $\begin{array}{l}\text { Build on existing, well-functioning policies (e.g. renewable energy, energy efficiency, agroforestry, and disaster } \\
\text { risk reduction) as an entry point for designing policies to support action on MSMEs' climate resilience as well. }\end{array}$ & $\begin{array}{l}\text { Governments with } \\
\text { support of dev-co }\end{array}$ \\
\hline & $\begin{array}{l}\text { Consider updating business- and trade-related regulations and policies in ways that are coherent with efforts } \\
\text { towards greater resilience of MSMEs to climate risks. }\end{array}$ & $\begin{array}{l}\text { Governments with } \\
\text { support of dev-co }\end{array}$ \\
\hline & $\begin{array}{l}\text { Multiply efforts to build the resilience of informal-sector businesses through social protection schemes, support } \\
\text { in the formalisation, enhanced access to basic infrastructure (e.g. water, drainage and electricity), among others. }\end{array}$ & $\begin{array}{l}\text { Governments with } \\
\text { support of dev-co }\end{array}$ \\
\hline \multicolumn{3}{|c|}{ Climate and weather data and information } \\
\hline & $\begin{array}{l}\text { Encourage national meteorological offices to engage with MSMEs and entities that support them (e.g. economy } \\
\text { ministries) as users of data and information to make sure of their usability for decision making. }\end{array}$ & Gover \\
\hline & $\begin{array}{l}\text { Invest in systems and processes of producing long-term climate projections to foster understanding of potential } \\
\text { impacts of climate change on MEMSs' business risks and opportunities (e.g. identifying marketable crops that } \\
\text { may flourish in future climate conditions). }\end{array}$ & $\begin{array}{l}\text { Governments with } \\
\text { support of dev-co }\end{array}$ \\
\hline & $\begin{array}{l}\text { Foster collaboration among businesses, universities and research institutions to support MSMEs' capabilities in } \\
\text { assessing and understanding climate risks, and collecting context-specific information on MSMEs' vulnerabilities. }\end{array}$ & $\begin{array}{l}\text { Governments and } \\
\text { dev-co }\end{array}$ \\
\hline & $\begin{array}{l}\text { Raise awareness among MSMEs about the need to strengthen climate resilience by using plain words that are } \\
\text { easily digestible by businesses and households. }\end{array}$ & $\begin{array}{l}\text { Governments and } \\
\text { dev-co }\end{array}$ \\
\hline \multicolumn{3}{|c|}{ Finance for strengthening climate resilience } \\
\hline & $\begin{array}{l}\text { Allocate finance to measures that build MSMEs' climate resilience and push other development agendas in a } \\
\text { coherent and gender-responsive manner. }\end{array}$ & $\begin{array}{l}\text { Governments and } \\
\text { dev-co }\end{array}$ \\
\hline & $\begin{array}{l}\text { Work with national development banks and/or funds to further engage with private-sector financial institutions to } \\
\text { scale up financing for MSMEs' action on climate resilience. }\end{array}$ & $\begin{array}{l}\text { Governments and } \\
\text { dev-co }\end{array}$ \\
\hline & $\begin{array}{l}\text { Engage with private-sector insurance companies to pilot insurance products (e.g. index-based insurance) and } \\
\text { disseminate them through various channels (e.g. micro-enterprises and co-operatives embedded in } \\
\text { communities), while enhancing enabling policies to develop domestic insurance markets. }\end{array}$ & $\begin{array}{l}\text { Governments with } \\
\text { support of dev-co }\end{array}$ \\
\hline
\end{tabular}

Note 1: Actions in this list are indicative and some of them may not be relevant to all countries or development co-operation providers Note 2: Dev-co - providers of development co-operation 


\section{Approaches to engaging the private sector in strengthening climate resilience}

This chapter presents key findings from the case studies on Guatemala, the Philippines and Senegal on how their governments and development cooperation partners are engaging with the private sector in strengthening its climate resilience. The chapter first discusses the importance of enhancing the resilience of the private sector to climate change, and different roles private sector actors have already been playing. It subsequently proposes possible ways forward on how governments and development co-operation providers can further enhance private-sector engagement to promote climate resilience in the pursuit of sustainable development in the three case study countries and beyond. 


\subsection{Strengthening climate resilience of the private sector for sustainable development}

The impact of climate change, compounded with other stressors such as poverty and inequality, is already threatening the ability of countries to achieve sustainable development objectives (OECD, 2019[1]; Hallegatte et al., 2016[2]). Transitioning to a low-carbon, climate-resilient economy to achieve sustainable development requires a major shift in the way both the public and private sectors act and invest. The need for such a shift has become even more pressing, as the COVID-19 pandemic has disrupted the global economy and development at every level and governments are responding to the consequences of the crisis (OECD, 2020[3] $)$. In addition, climate hazards, increasing in frequency and intensity, are intersecting with the COVID-19 pandemic and public health responses in many developing countries such as the Philippines and Guatemala, as well as Fiji, Vanuatu, the Solomon Islands, Tonga, to name a few (Phillips et al., 2020[4]). In Africa, changes in precipitation levels, increases in extreme heat and sea-level rise are already having a wide range of direct and indirect impacts at the same time as the countries respond to the health and economic impacts of the COVID-19 pandemic (Africa Adaptation Initiative, 2020[5]).

The private sector is a crucial actor to ensure the transition to a low-carbon and climate-resilient economy. The recovery efforts for the post-COVID-19 crisis are likely to influence, and be influenced by, action to manage the rising impacts of climate change, implying a greater limitation to the fiscal space of governments for at least a decade (OECD, 2020[6]). Deeper and broader engagement with the private sector in approaches towards climate resilience was already emerging before the crisis - from large corporations to small businesses, as well as groups that represent their interest such as industry associations, chambers of commerce and co-operatives (see the case studies ${ }^{1}$ as well as (UNDP, n.d. [7]; Schaer and Kuruppu, 2018 ${ }_{[8]}$; Crawford, Church and Ledwell, 2020[9]) for examples).

Private sector actors continuously adjust their business operations to the changing context of their business environment, whether it is caused by climate change or not (e.g. farmers have adapted their crop types to changes in their environments for centuries). Climate change, however, is likely to make such adjustments even more challenging. The causes of the challenge are diverse, including:

- uncertainty of predicted impacts of climate change on individual businesses and their contexts;

- significant increase in frequency and intensity of extreme events

- policy frameworks that do not adequately take into account the social costs of climate change (e.g. in land-use regulations, agriculture input subsidies, water tariff systems);

- limited knowledge among businesses about climate risks, opportunities and potential solutions;

- limited access of informal businesses to technical and financial support for risk reduction measures (UNDP, n.d. $[7]$; Schaer and Kuruppu, 2018[8]; Crawford and Church, 2019[10]).

These issues above suggest a further scope for enhancing the enabling environments for the private sector to adapt and respond to climate-related hazards through awareness raising, development and provision of data and information, as well as regulatory and policy reforms. Enhancing these would also help more businesses realise that action on climate resilience directly relates to their interest to remain viable and profitable.

The COVID-19 pandemic and its economic impacts also pose additional challenges for the private sector to build climate resilience. One of the challenges is the shift in some countries' national priorities from climate action and environmental protection, to the urgent humanitarian and health needs, as well as action to reboot the economy (Vivid Economics, 2020[11]; GCA, 2020[12]). These responses to humanitarian, health and economic emergencies are sensible. Businesses, especially micro, small and medium-sized

\footnotetext{
1 The summaries are available in Chapter 2 of the report, while more detailed studies will be uploaded to https://www.oecd.org/development/climate-resilience/
} 
enterprises (MSMEs) suffer from a reduction in the supply of labour, and consumers losing income, spending and consumption. Yet, the crisis also affords the opportunity to rethink current economic and development models in ways that take into account the barriers for the private sector to engage in climaterelated issues - if only the recovery packages are designed to do so.

\subsection{Need for greater engagement with the private sector}

Active engagement with diverse stakeholders, including the private sector, is an essential part of inclusive and locally led approaches to strengthen climate resilience and to achieve sustainable development of a country (see Box 1.1. for key concepts adopted in this report). The notion of the private sector engagement includes collaboration and partnerships between the private sector and governments or development co-operation, or both. Private sector collaboration and partnerships aim to promote the twin goals of enhancing companies' core business activities, while meeting sustainable development objectives (Crishna Morgado and Lasfargues, 2017 ${ }_{[13]}$ ). Private sector engagement also includes interventions by development co-operation and governments to develop the private sector per se. Private sector development activities aim to create and enhance enabling environments for the private sector to grow, such as conducive policies and incentives, as well as governance arrangements that address market failures, and direct firm-level interventions (e.g. capacity building, facilitating access to finance and markets). See Crishna Morgado and Lasfargues $\left(2017_{[13]}\right)$ for a broader discussion on engaging the private sector for green growth and climate action.

\section{Box 1.1. Concepts of climate resilience}

Resilience refers to the preventive and reactive capacity of social, economic and environmental systems to resist or absorb a hazardous event, trend or disturbance. Resilience helps respond in ways that maintain their essential functions, identity and structure. It also maintains the capacity to reorganise through learning, adaptation and transformation (IPCC, 2018[14] $)$ (Dornelles et al., 2020[15]).

Climate resilience is a component of the broader concept of resilience. Climate resilience refers to the capacity of human and natural systems to learn, adapt and transform in response to risks induced or exacerbated by climate change (OECD, $\left.2021_{[16]}\right)$.

This report uses the term 'climate risks' as a function of the exposure of people and assets to hazards - extreme weather and climate events (e.g. heavy downpours and strong winds) and slow-onset changes (e.g. drought and sea level rise) - and the vulnerability of the affected system (IPCC, 2019[17]). Climate risks can be either direct or indirect, both of which can cause negative impacts on the operations, profitability and continuity of MSMEs.

- Direct climate risks are related to the exposure and vulnerability of private sector assets and business processes. Direct risks in agriculture, for instance, include impacts on physical assets (e.g. damages on storage facilities), processes (e.g. flooding in a workshop that halts production) or inputs and resources (e.g. soil erosion) (UNDP, n.d.[7]).

- Indirect climate risks include disruptions to, for instance, infrastructure that provides essential services to business operations and their supply chain networks, availability of finance, and economic and political stability (UNDP, n.d.[7])

This report aims to examine how bilateral and multilateral providers of development co-operation and governments of developing countries can further engage with the private sector to strengthen its resilience to the impacts of climate change. Analysis in this report is informed by the good practices and lessons learnt in three case study countries: Guatemala, the Philippines and Senegal (Box 1.2) as 
well as desk research on other countries' approaches. Proposed policy recommendations target more directly approaches to strengthen climate resilience in these three case study countries. Nevertheless, many of the recommendations may also be relevant to a wider range of countries. There are several approaches to strengthening the climate resilience of businesses. The scope of this report includes both i) efforts to manage climate-related risks to business operations and assets, and ii) efforts to take advantage of potential business opportunities in providing products and services that can contribute to their users' resilience.

\section{Box 1.2. Case studies on Guatemala, the Philippines and Senegal}

The following work informed the development of this working paper: Three case studies on Guatemala, the Philippines and Senegal and a desk-base review of the broader literature on private-sector engagement in climate action. This paper also informed and complements the OECD publication, Strengthening Climate Resilience: Guidance for Governments and Development Co-operation, with perspectives on private-sector engagement in climate resilience building. (see: https://oe.cd/climateresilience)

The three case studies represent various income groups (Guatemala and the Philippines are lower middle-income countries, while Senegal is a least developed country) and regions (Central America, Southeast Asia and sub-Saharan Africa). The countries differ in their geographical and climatic contexts. Guatemala is largely mountainous except for the south coast and the vast northern lowlands, providing large contrasts between hot, humid tropical lowlands and colder, drier highland peaks. The Philippines is an archipelago composed of more than 7600 islands with a tropical maritime climate. Senegal is a West African country whose climate consists of warm desert climate in the north, warm semi-arid climate in the middle and tropical savannah climate in the south.

These countries, in collaboration with providers of development co-operation, have been taking initiatives to strengthen the climate resilience of the private sector to a varying extent, providing this study with several opportunities for learning.

This report focuses particularly on climate resilience of MSMEs, given their climate resilience as a key driver to promote growth, eradicate poverty and improve social equality in the three case study countries and many other developing countries. MSMEs contribute to a significant share of the economy and employment across the world, including in developing countries (ILO, 2019 [18]) (See also Box 1.3). Ninety-nine per cent of the total registered businesses are MSMEs in the Philippines, while they generate more than $60 \%$ of total employment. In Senegal, $90 \%$ of businesses are MSMEs contributing to $30 \%$ of the country's gross domestic product (GDP) and about $40 \%$ of total employment. In Guatemala, MSMEs contribute to at least $40 \%$ of GDP and $85 \%$ of employment. MSMEs are also an essential part of global value chains in, for instance, agriculture, fisheries, textile and manufacturing industries. This means that strengthening MSMEs' resilience and ensuring their business continuity can help both mitigate the negative impacts of climate change on their operations and prevent the disruption of global supply chains and markets (UN Environment, 2018[19]).

MSMEs are often more vulnerable to the impacts of climate variability and change than larger enterprises are (Crick et al., 2018[20]; Mavrodieva et al., 2019 ${ }_{[21]}$ ). MSMEs face various constraints to building climate resilience in the case study countries. For instance, they tend to have lower levels of capacity in understanding climate risks than those of large enterprises, and greater challenges to accessing affordable credits and insurance, or fiscal support. MSMEs also often have more limited knowledge on appropriate measures to manage climate risks to their businesses. MSMEs also tend to be more exposed to climate-related hazards. For instance, many MSMEs operate in the informal sector out of necessity, and are often more likely to be located in risk-prone areas in the three case study countries 
and beyond (Crawford, Church and Ledwell, 2020[9]; Schaer and Kuruppu, 2018[8]). These challenges related to capacity and exposure are also common in many other developing countries (Dougherty-Choux et al., 2015[22]; Crick et al., 2018[20]). Relating to these challenges, MSMEs often take unsustainable responses to disasters, such as the distress sale of assets, which often results in a contraction in business activity (Crick et al., 2018[20]).

\section{Box 1.3. Definition of MSMEs}

MSMEs are non-subsidiary, independent firms that employ less than a given number of employees the number varies across countries. The most frequent upper limit designating a MSME is 250 employees. Small firms are generally those with fewer than 50 employees and micro-enterprises have at most 10 , or in some cases 5 , workers. For a more detailed definition of MSMEs, see for instance (OECD, 2005[23]) and Chapter 7 of (OECD, 2018[24]).

Source: (OECD, 2018 $\left.{ }_{[24]}\right)$, Chapter 7: The private sector and the catalytic role of micro, small and medium-sized enterprises (in Development Co-operation Report 2018: Joining Forces to Leave No One Behind), https://dx.doi.org/10.1787/dcr-2018-en

\subsection{Motivation and challenges for the private sector to act on climate resilience}

MSMEs are increasingly considering climate change a significant risk to the profitability and continuity of their businesses in the case study countries and other developing countries (Crawford and Church, 2019 [10]; CICA, 2019[25]; Schaer and Kuruppu, 2018[8]; UNDP, n.d.[7]). Good practices by the private sector, including MSMEs, to strengthen climate resilience have been emerging over the past decade, so are lessons learnt. Many of the initiatives have taken place in co-operation with the public sector, development co-operation providers and other non-state actors such as civil society organisations, academia and foundations to name a few (UNDP, n.d. [7]; Schaer and Kuruppu, 2018[8]; LIFE-AR, 2019 [26]).

There are varying motivations for MSMEs to strengthen their climate resilience, owing to their sizes, sectors, business and operation models, location and capacity. Some businesses adapt their own operations to make them resilient to a changing climate, while others aim to seize business opportunities that may be driven by evolving needs for goods and services in support of climate resilience. The case studies of this report revealed that many businesses in the three countries take action on climate resilience as the extension of business risk management. Examples include purchasing agricultural insurance and developing business continuity plans for retail supply chain management against disasters. Many MSMEs may also work on climate resilience only to respond to regulatory requirements regarding environmental protection, disaster risk reduction and land-use management inter alia. Some companies take such action to generate returns and explore new markets such as the development and production of new goods and services. Such new goods and services may include climate-resilient crop seeds, the provision of climate and weather data and information, climate-resilient tourism, and water-efficient irrigation systems.

Opportunities for MSMEs to develop revenue-generating business models around climate resilience exist, but remain limited in scale in the case study countries. As discussed in the previous section, several barriers still remain to scaling up such good practices by MSMEs in managing climate risks, including those related to capacity to adapt and cope, exposure to hazards and access to resources. Provision of the right policy incentives helps to ensure that climate resilience can be seen by the private sector as an area where business opportunities can be made and upon which MSMEs can turn to thrive and consolidate their operations. The case studies observed some emerging entry points: for instance, fostering climate resilience by looking at interlinkages with climate mitigation activities. In Senegal, 
increased installation of solar panels have improved energy access of businesses in recent years, allowing them to ensure continuity of their operations and their resilience to power cuts caused by, for instance, weather-related disasters.

Many MSMEs in the case study countries are well aware that they are vulnerable to impacts of climate change. Yet, they may not always be aware of what action they can take with their capacities. Even when MSMEs are willing to take initiatives to build climate resilience, many of them tend to lack financial, technology and human resources. This point was commonly observed in all three case study countries. For instance, smallholder farmers in Guatemala and Senegal are feeling the impacts of climate change and would be keen to enhance their resilience, but find it difficult to develop or change prevailing business models. When the affordable risk management solutions are made available, MSMEs might quickly opt in. In Senegal, the insurance sector is increasingly targeting MSMEs in the agricultural and fishery sectors. Another observation from the Senegal and Guatemala studies is that many MSMEs often consider that planning and implementing activities for climate resilience are the role of the governments or larger companies.

Governments and development co-operation providers have an important role to play in addressing these challenges through their policy and financial interventions for private sector development, as well as through collaboration and partnerships with the private sector. Many of the measures that support development of the private sector in general are also relevant to efforts to strengthen climate resilience of MSMEs. Examples of such measures include provision of market-relevant information, training on managerial and sector-specific skills, and facilitating access to finance. Further, the private and public sectors are already collaborating in many developing countries, including the case study countries, for building their climate resilience to achieve sustainable development. To acknowledge some of the climate-related initiatives various private-sector actors have already been taking, section 1.4 outlines the roles of private sector actors in strengthening their climate resilience, based on the case studies. Section 1.5 then discusses how engagement between the private sector, governments and development co-operation providers could be further improved to build MSMEs' resilience to climate change in the light of broader development objectives in the case study countries and potentially also in other developing countries.

\subsection{Varying roles of the private sector in strengthening climate resilience}

Exploring approaches to the resilience of private-sector actors requires due attention to the diversity of their interests and capacities in acting on climate risk, and their business and socioeconomic contexts. For instance, both large enterprises and MSMEs can manage their risks by investing in their business assets (e.g. production facilities and equipment) and operational processes in ways that are resilient to the impacts of climate change. Financial institutions can offer financial solutions, where financially viable, such as bank loans, microfinance and insurance. Clients of those financial institutions can then use the financial instruments to make their assets and operations more adaptive to climate change, or have their assets insured against disasters. Business associations such as chambers of commerce can co-ordinate and promote activities to increase awareness of climate risks among their member companies and provide them with opportunities to enhance capacities.

Large enterprises and MSMEs can support each other in strengthening their climate resilience through, for instance, their supply chains. In the Philippines, large retail companies (e.g. the SM Malls) have supported their tenants, many of which are MSMEs, in developing business continuity plans as part of risk management against extreme weather events. In Senegal, some large banks (e.g. BNP Paribas) provide credit lines to MSMEs as part of their corporate social responsibility (CSR) programme. This programme, motivated by their reputation management, has contributed to climate action by small businesses in particular. Guatemala's sugar producer association has created its Climate Change Institute, 
which produces climate-related data and information. The institute supports MSMEs in the agriculture sector with capacity building, providing risk assessment tools and training modules on climate resilience, with the intention of protecting the sugar value chain.

Reflecting the diversity of MSMEs and private-sector actors more broadly, their role in strengthening climate resilience can differ from one actor to another, including as an implementer of actions, facilitator of collaboration and provider of data, information and finance. This report frames the following four types of roles that have either direct or indirect impacts on MSMEs' climate resilience:

- implementers of action,

- facilitators of collaboration,

- providers of data and information and

- providers or intermediaries of finance.

Based on this framing, Table 1.1 illustrates different types of private sector actors, and examples of their respective roles in strengthening climate resilience of the private sector. The subsequent section provides further details on each of these roles.

\section{Table 1.1. A typology of private sector actors and their roles in action on climate resilience}

\begin{tabular}{|c|c|c|c|c|c|c|}
\hline $\begin{array}{l}\text { Sectors and } \\
\text { groups }\end{array}$ & Type of private-sector actors & 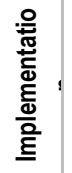 & 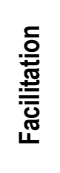 & 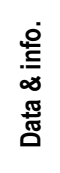 & 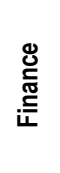 & Further descriptions based on the case studies \\
\hline \multirow[t]{2}{*}{$\begin{array}{l}\text { Non-financial } \\
\text { institutions }\end{array}$} & Large-scale enterprises & $\checkmark$ & $\checkmark$ & $\checkmark$ & $\checkmark$ & $\begin{array}{l}\text { Implement own initiatives in climate resilience; form } \\
\text { networks to collaborate with other public and private } \\
\text { entities; provide technical and financial support to } \\
\text { MSMEs through supply chains; provide weather- } \\
\text { and/or climate-related information complementing the } \\
\text { role of national meteorological offices. }\end{array}$ \\
\hline & $\begin{array}{l}\text { Micro, medium and small-sized } \\
\text { enterprises }\end{array}$ & $\checkmark$ & $\checkmark$ & & & $\begin{array}{l}\text { Implement own initiatives; form coalitions with other } \\
\text { MSMEs and large companies around common } \\
\text { interests (e.g. exchange knowledge and information, } \\
\text { participation in policy making processes, etc.); } \\
\text { provide input to local-level climate risk and } \\
\text { vulnerability assessments. }\end{array}$ \\
\hline \multirow[t]{2}{*}{$\begin{array}{l}\text { Financial } \\
\text { institutions }\end{array}$} & $\begin{array}{l}\text { Commercial banks and other non-bank } \\
\text { financial institutions }\end{array}$ & $\checkmark$ & & & $\checkmark$ & $\begin{array}{l}\text { Design and provide loan and other financial products } \\
\text { to be used for measures by MSMEs on climate } \\
\text { resilience }\end{array}$ \\
\hline & Insurance and re-insurance companies & $\checkmark$ & & $\checkmark$ & $\checkmark$ & $\begin{array}{l}\text { Develop and provide insurance against climate and } \\
\text { other risks to MSMEs; potentially provide data that } \\
\text { complements information from public actors }\end{array}$ \\
\hline $\begin{array}{l}\text { Business } \\
\text { associations } \\
\text { and their } \\
\text { networks }\end{array}$ & $\begin{array}{l}\text { Chambers of commerce, sector/industry } \\
\text { associations, employers' associations, } \\
\text { associations of banks/insurance } \\
\text { companies/microfinance organisations, } \\
\text { etc. }\end{array}$ & $\checkmark$ & $\checkmark$ & $\checkmark$ & & $\begin{array}{l}\text { Implement trainings and organise workshops for their } \\
\text { members; facilitate collaboration between the } \\
\text { government and other public and private stakeholders } \\
\text { to help MSMEs build resilience }\end{array}$ \\
\hline $\begin{array}{l}\text { Business } \\
\text { support } \\
\text { services }\end{array}$ & Start-up incubators & $\checkmark$ & & $\checkmark$ & & $\begin{array}{l}\text { Support social enterprises that provide innovative } \\
\text { products and services that can contribute to MSMEs' } \\
\text { resilience. }\end{array}$ \\
\hline
\end{tabular}

Note: 'Data \& info.' means the private sector's role as a provider of data and information

Source: Authors' elaboration based on the case studies on Guatemala, the Philippines and Senegal 


\section{As an implementer of action}

Many private-sector actors, including MSMEs, are already implementing certain activities to strengthen their climate resilience in the case study countries, although those activities may not primarily be motivated by the awareness of climate risks. Businesses invest their own funds in measures that enhance their climate resilience, if the measures are economically rationale and affordable. In Guatemala, for instance, many in export-oriented sectors (e.g. sugar, coffee and cocoa industries) invest in climate resilience autonomously, as a means to ensuring minimal disruptions to their supply chains when hazards strike. In Senegal, the tourism sector invested in mangrove and beach restoration and preservation to ensure business continuity in the face of coastal erosion. These actions have been implemented, often without financial support from governments or development co-operation. Outside the case study countries, a study shows that fisherfolks in Thailand has invested in cultivating rubber, oil palms and orchards to diversify their livelihoods and thus to build their resilience to the negative impacts of climate change on their fishing activities (Sereenonchai and Arunrat, 2019 [27] $_{\text {). }}$.

Private-sector actors often work with governments and development co-operation providers to support implementation and upscaling of public-sector initiatives. For instance, Senegal has a publicprivate insurance company, the Compagnie Nationale d'Assurance Agricole du Sénégal (CNAAS), specialised in providing risk insurance solutions for farmers. The shareholders of CNAAS include the Senegalese government, insurance companies, the Banque Agricole (a commercial bank) and farmer associations, providing insurance products covering several phases of farm production (CICA, 2019[25]).

\section{As a facilitator of collaboration}

The private sector often takes initiatives in facilitating collaboration across different actors in the private and public sectors, as well as civil society to promote exchange of knowledge about good practices and lessons learnt in building climate resilience. Yet, the degree of such exchange greatly varies among the three countries. The case studies revealed that platforms where private-sector actors can meet and share lessons and good practices are helpful for MSMEs, but their processes, membership, format and participation processes should be carefully designed. In the Philippines, annual forums on resilience of MSMEs have been organised by several private-sector actors, such as the Private Sector Alliance for Disaster Resilient Societies (ARISE Philippines), the Philippine Disaster Resilience Foundation, and the Ayala Foundation. This forum has facilitated peer-learning on good practices and lessons learnt among business leaders, representatives of MSMEs, and other public and private-sector practitioners working on business continuity plans. In Guatemala, on the contrary, private sector roundtables were established, but some stakeholders considered them to be dysfunctional due to the format (not being interactive enough) and composition (seen as gathering too many actors, with differing motivations and interests).

Business associations are often promoting and co-ordinating climate action by various privatesector actors, and fostering their collaboration with governments and development co-operation. In some cases, those business associations (e.g. chambers of commerce, business and farmers associations, bankers associations) also organise training activities to enhance capacity of their respective members. For instance, the Philippines Chamber of Commerce and Industry supports MSMEs in capacity development on disaster risk reduction through business continuity management. Similarly, in the case of Guatemala, the business associations of sugar or coffee producers have taken action to increase the resilience of businesses operating in these value chains. Business associations can also channel interests of their member companies in policy-making processes, by participating in relevant policy dialogue and co-ordination mechanisms at national and sub-national levels. This role has been observed in the Philippines (e.g. development of the National Roadmap for MSME Disaster Resilience), and to a lesser degree, in Guatemala and Senegal. 
Large enterprises may also support their MSME partners, and co-ordinate efforts to strengthen their climate resilience as part of supply chain management. For instance, a large retail chain in the Philippines called SM Supermall supports its MSMEs partners (tenants of its shopping malls) in business continuity management against disasters. Large enterprises can also play an important role in facilitating engagement between governments, development co-operation providers and informal-sector MSMEs, as well as underserved actors such as women-led businesses. Such engagement is also often driven by CSR of the large enterprises. For example, UN Women worked with the Banque Internationale pour le Commerce et I'Industrie du Sénégal (a subsidiary of BNP Paribas) to provide micro credit lines to strengthen climate resilience of women-owned businesses, as part of the bank's corporate social responsibility programme.

\section{As a provider of data and information}

While the public sector is generally the primary source for climate and weather data and information, the private sector can complement the roles of national meteorological offices in the case study countries. In the case study countries, some private-sector actors generate and disseminate weather and climate data and information. In the case of Senegal, the National Agency for Civil Aviation and Meteorology (ANACIM), collaborates with private sector actors that are also the end users of climaterelated information. For example, some of these end users are smallholder farmers in semi-arid lands in the Senegal River valley. The ANACIM has studied the needs of these users (e.g. granularity and types of information needed, languages and modalities of delivery for the climate information), in collaboration with development co-operation providers. The Guatemalan Sugar Association has created the Institute for Climate Change Research (ICC) that produces climate related data, information and capacity building, partly complementing the role of the National Institute for Seismology, Vulcanology, Meteorology and Hydrology of Guatemala (INSIVUMEH) (See Box 1.4). The WeatherPhilippines, an initiative run by a private philanthropy called the Aboitiz Foundation, used to provide short-term weather forecasts for free, which complemented longer-term information provided by the Philippine Atmospheric, Geophysical and Astronomical Services Administration (PAGASA). Several large enterprises had contributed to the Aboitiz Foundation as part of their CSR frameworks.

\section{Box 1.4. Private-sector initiatives in providing climate and weather data and information in Guatemala}

In Guatemala, Asazgua (Guatemalan Sugar Association) has created the Institute for Climate Change Research (ICC) that produces services to support action on climate resilience of its members (e.g. data, information and capacity building). The institute's support complements, if not replaces, the information provided by the INSIVUMEH, which has a narrow mandate and limited resources to cover all potential beneficiaries with climate-related information and trainings. The Centre for Action of Corporate Social Responsibility in Guatemala (CentraRSE), Action Against Hunger (ACH), the Centre for Natural Disasters prevention in Central America (CEPREDENAC) and the ICC have recently launched a virtual course on disaster risk management and reduction and biosafety for entrepreneurs, SMEs and large companies (ICC, 2020[28]).

The case studies also illustrate certain challenges faced by the private sector in providing data and information that are in principle public goods. For example, while MSMEs need access to affordable (or free) data and information, this may undermine the financial sustainability of private-sector initiatives in providing such data and information. The above mentioned WeatherPhilippines closed its operations in 2020, and the parent organisation, the Aboitiz Group, donated its automated weather stations and other weather technology assets to various government agencies, local government units and a civil society 
organisation (Aboitiz, 2020[29]). There were multiple reasons for the closure, but financial constraint was among them. In Senegal, on the contrary, small start-ups (e.g. PayDunya, Niokobok) are filling the gaps left by large telecommunications operators to deliver paid climate-related data and information to end users in the agriculture or fisheries sector. As some of these larger operators are slow and/or relatively expensive to deliver the information, these start-ups ensure end users are able to receive the said information in a timely and affordable manner. Here the challenge is one of limited digitalisation rates in the country for these start-ups to thrive, as not all end users use digital technologies to access this information.

In climate risk and vulnerability assessments, private-sector actors can also provide locally specific information (e.g. knowledge of sensitivity and exposures of local MSMEs' assets and business operations to climate-related hazards). This information is tailored to local contexts and concerns the situation of markets and supply chains, as well as other socio-economic and political contexts, within a community in question. Several studies acknowledge the importance of taking such locally generated information into consideration when planning and implementing approaches to strengthening the climate resilience of MSMEs (Weaver et al., 2017[30]; Ford et al., 2018[31]; Crawford, Church and Ledwell, 2020[9]). For example, the World Food Programme (WFP) supports vulnerable Indigenous communities of Guatemala, often composed of micro enterprises in the agriculture sector. WFP enhances their resilience through 'community calendars', which helps to understand where the community is and when a disaster is likely to strike (e.g. planting, harvesting, processing). This helps tailor the support provided to the community and to preserve the local economy when a disaster hits.

In practice, however, granular local-level data and information on climate hazards and MSMEs' vulnerability are often lacking, or difficult to obtain. For example, some interviewees in the Philippines underscored the need for enhancing information on MSMEs' businesses, assets and their locations, as well as data on damages during past disasters. These kinds of information are in many cases unavailable in sufficient quality. In Guatemala, certain export-oriented sectors are geared towards reducing climaterelated vulnerabilities - e.g. in sugar, coffee and cocoa industries. The value chains in these sectors gather the data needed to prepare and react during a disaster to maintain exports and market access. Yet, it remains challenging to scale up such effort beyond these sectors in the country despite its populations' exposure to a variety of natural hazards, including floods, droughts, volcanic eruptions and earthquakes.

\section{As a provider or an intermediary of finance}

Financial institutions, such as commercial banks, microfinance and insurance companies, can help MSMEs build their climate resilience with their financial solutions. Some commercial banks provide finance for climate resilience through different forms of financial instruments along with relevant capacity building and awareness raising activities in the case study countries. In Senegal, the Banque Agricole, one of the largest banks in the country, introduced obligatory agricultural insurance for loans to farmers. Other commercial banks operating in Senegal have also been providing loans to acquire solar-powered water pumps and domestic biogas systems for some years, although few banks have offered such loans to climate-resilience related projects. In Guatemala, the Catastrophe Risk Organisation (MiCRO) provided the first index-based insurance for micro and small businesses against drought, excess rainfall and earthquakes. MiCRO co-operates with Guatemala's National Coordination for Disaster Reduction (CONRED) to help businesses mitigate risks and become more resilient through information and incentives (MiCRO, 2017[32])

Apart from those champions, the case studies reveal that incentives for many private-sector financial institutions to mobilise finance for MSMEs' climate resilience activities remain limited. Commercial banks in the case study countries tend to focus their operations on clients emanating from the formal private sector. Most MSMEs, however, operate in the informal sector, and are perceived as potential clients with greater default risks. As a result, domestic financial institutions, especially commercial banks, have been reluctant to provide affordable lending to MSMEs, whether it is climate-related or not. In the 
Philippines, this tendency has been observed despite the legal requirement for banks to lend a certain percentage of their loan portfolios to MSMEs.

On the demand side, businesses, especially MSMEs, tend to consider that the returns on investment in their climate resilience are too uncertain, hence are not motivated to take commercial loans. This is mainly due to uncertainty in future projections of climate change impacts and related changes that might occur to their businesses and supply chains. As a more general development challenge, most informal-sector MSMEs do not even have bank accounts, hence they lack access to formal financial instruments. Microfinance institutions, in some cases with support of development banks, have been playing an important role in supporting access of small businesses to finance (e.g. The Genesis Business Foundation, a provider of microfinance in Guatemala, is working with the IDB Invest to provide mid to long-term loans to MSMEs (IDB Invest, 2020[33])). Enhanced policy incentives and alternative financing models (e.g. blended finance and public-private partnership) can also mitigate such barriers and will be discussed in the next section.

\subsection{Ways forward to enhance private sector engagement in building climate resilience}

This section examines how governments and development co-operation providers can further enhance their approaches to strengthen the climate resilience of MSMEs. The ways forward proposed in this section draw from the three case studies conducted for this report, but may also be relevant to a broader range of countries. This section focuses on four aspects, namely: institutional arrangements and networks, enabling policies, data and information, and finance. Table 1.2 summarises the rationales for including these four aspects as areas where governments and development co-operation providers can enhance their engagement with the private sector to support MSMEs' climate resilience.

Table 1.2. Key aspects for greater engagement with the private sector in climate resilience building

\begin{tabular}{l|l}
\hline \multicolumn{1}{c|}{ Aspect } & \multicolumn{1}{c}{ Rationale for inclusion in the report } \\
\hline $\begin{array}{l}\text { Institutional } \\
\text { networks }\end{array}$ & $\begin{array}{l}\text { Strengthening climate resilience requires establishing and operationalising an effective and inclusive institutional } \\
\text { arrangement that co-ordinates actions across ministries and levels of government, as well as among a broader range of } \\
\text { stakeholders, including the private sector (e.g. individual businesses and business associations). Inclusive governance and } \\
\text { networks are key to support locally led initiatives in building climate resilience, including those by the private sector. }\end{array}$ \\
\hline Enabling policies & $\begin{array}{l}\text { Policy frameworks at national, local and sectoral levels can influence (e.g. require, encourage or discourage) decision } \\
\text { making by private-sector actors on climate resilience. Efforts to strengthen climate resilience require explicit consideration } \\
\text { of challenges caused, and opportunities created, by climate change in planning, implementation and reviewing a country's } \\
\text { policy frameworks. They in turn influence cost-benefit profiles of activities that can potentially be taken by the private sector } \\
\text { to manage climate risks. }\end{array}$ \\
\hline Data and \\
information & $\begin{array}{l}\text { Efforts by the private sector to strengthen climate resilience rely on the availability of useful and legitimate weather and } \\
\text { climate data and information, as well as local information on vulnerability and other socio-economic factors. The private } \\
\text { sector can also provide such data and information. }\end{array}$ \\
\hline Finance & $\begin{array}{l}\text { Finance is a crucial enabler for structural (e.g. purchase of equipment and infrastructure investment) and non-structural } \\
\text { (e.g. development of policies, capacity, data and information) measures. The private sector is both a user and a provider of } \\
\text { finance, complementing the role of domestic budgets and development finance. }\end{array}$ \\
\hline
\end{tabular}

Source: Authors' own based on (OECD, 2021 $\left.{ }_{[16]}\right)$, Strengthening Climate Resilience, https://doi.org/10.1787/4b08b7be-en, (OECD, 2017[34]), Getting Governments Organised to Deliver on the Sustainable Development Goals: High Level Political Forum, http://www.oecd.org/gov/SDGsSummary-Report-WEB.pdf and (OECD, 2009[35]), Integrating Climate Change Adaptation into Development Co-operation: Policy Guidance, https://dx.doi.org/10.1787/9789264054950-en 


\section{Institutional arrangements and networks}

Governments and development co-operation can further enhance institutional arrangements to engage the private sector in strengthening MSMEs' climate resilience. However, approaches to the engagement will be highly context specific. Varying forms of institutional arrangements and networks are in place, which directly or indirectly aim to foster climate resilience of the private sector in the case study countries (see the list below for some examples). Governments and development co-operation providers may benefit from a clearer understanding of relevant stakeholders through, for instance, a mapping exercise focusing on their roles and needs in resilience building (Crawford, Church and Ledwell, $\left.2020_{[9]}\right)$. A greater availability of such information to broader government entities and development cooperation providers could provide a useful basis for discussion among them on approaches to greater engagement with MSMEs in strengthening climate resilience.

- In the Philippines, the institutional arrangement targeting MSMEs' resilience consists of vertical and horizontal networks of public and private sector actors, as well as civil society organisations and development co-operation providers. Several initiatives and institutions already exist, including the MSME Resilience Core Group (co-hosted by the Department of Trade and Industry and the Philippines Chamber of Commerce and Industry), the National Resilience Council and the ARISE Philippines to name a few.

- In Senegal, the National Committee on Climate Change (COMNACC) integrates private sector actors to discuss climate resilience issues. The Committee is supposed to receive information related to climate risks from regional-level committees (the COMRECCs). Other bottom-up initiatives by start-ups and social enterprises in climate resilience are also emerging in Senegal. Nonetheless, their scale tends to be small and interactions among the firms and initiatives remain limited compared to the Philippines.

- In Guatemala, activities directly or indirectly related to the resilience of MSMEs are largely government-led and top-down. The country has put in place the National Climate Change Council, chaired at the highest level by the President. However, there are also notable initiatives by nonstate actors such as the ICC as mentioned in Box 1.4 and section 2.1.

In some cases, there is a proliferation of public and private institutions and their initiatives related to MSMEs' resilience. Governments may consider creating a platform, or reinforcing an existing institution, to efficiently co-ordinate actors and initiatives to support MSMEs and their climate resilience. A plethora of MSME support institutions may reflect a diversity of needs and priorities among different actors. At the same time, this may cause a confusion among MSMEs in seeking support, or blurred responsibilities among similar institutions. A suggestion emerging from the Senegal case study was to establish a "onestop-shop" platform where different support programmes for MSMEs, including from development cooperation providers, would be co-ordinated, and where climate resilience considerations could be incorporated. Also in the Philippines, some interviewees, while acknowledging the diversity of needs and priorities among different actors, have stressed the need for a "central co-ordinator" of a number of ongoing initiatives in building MSMEs' resilience. There are more than 1000 so-called "Negosyo Centers" across the Philippines that already provide support to MSMEs with business-related tools and trainings, including on business continuity management. While not a central co-ordinator, Negosyo Centers can potentially be used as a platform where MSMEs can take trainings and receive support related to climate resilience.

Governments and development co-operation providers may deepen their collaboration with business associations to set a common vision on priorities for fostering MSMEs' climate resilience, facilitate co-ordination among initiatives, and facilitate the learning between MSMEs. Good practices in collaboration with business associations are emerging in the case study countries, such as in exchange of knowledge, facilitation of public-private partnerships, support provision of climate data and information (see Box 1.5 for examples from the case study countries). These business associations include chambers of commerce, industrial associations, co-operatives, associations of employers, of small farmers and of 
banks, as well as networks of women-led businesses and start-ups. Business associations and their networks could help connect MSMEs with governments and development co-operation providers, channel technical or financial support to businesses, and collect data and information for the development of policies and projects. Collaboration with local business associations and their networks could also be expanded to include broader types of organisations, such as civil society organisations. For instance, Christian Aid worked with local women-led community groups in the Philippines on resilience to tackle persisting poverty and inequality aggravated by disasters and the risks of climate change for four decades (Christian Aid, n.d.[36]).

The advocacy role of business associations in aggregating the voices of local MSMEs and bringing their views to governments' policy-making processes can be valuable for those focusing on strengthening climate resilience. For governments and development co-operation providers, reaching out to MSMEs is time and cost-intensive. Leveraging local business associations and networks can help governments and development co-operation providers to collect information on vulnerability, needs and priorities of their members, as well as good practices and successful initiatives.

The case studies observed some emerging good practices by the private sector in forming coalitions among MSMEs, based on their common interest in resilience building. The MSME Disaster Resilience Forum in the Philippines, for instance, has facilitated a participatory process across the private and public sectors to develop a roadmap that outlines key actions, relevant actors, potential pilot initiatives and timelines to promote measures on MSMEs' resilience. The Groupements d'Intérets Economiques of Senegal bring together micro and small peanut farmers to benefit from a greater bargaining power when producing, transforming and selling goods. They also benefit from economies of scale when signing loan or insurance contracts, as they are signed by the group as a whole (rather than by individual firms). Sugar and coffee farmers in Guatemala have garnered notable political bargaining power by organising themselves and forming coalitions that have common interests and objectives. In some areas of Guatemala, local MSMEs and their networks are the only ones that have done any work on resilience, thus they may be among the few sources of information that could support the government in further developing policies that appropriately consider climate hazards and vulnerabilities on the ground. 


\section{Box 1.5. Examples of business associations and their networks for strengthening climate resilience}

In Guatemala, the Chamber of Industries of Guatemala (CIG) together with the Union of Companies of Environmental Products and Services (GEPSA) have launched an Environmental Forum bringing together over 200 actors from public, private and academic spheres at national and international levels to share knowledge and good practices (CIG, 2019 ${ }_{[37]}$ ). MSMEs make up $80 \%$ of CIG's members and CIG provides policy advice to the government on MSME issues. In addition, a government-led Climate Change Council also exists and includes the private sector. However, the Council has not convened regularly, mainly because only the President of the Republic can call for a Council meeting. This has made private initiatives even more important in the Guatemala context, though ideally stakeholders noted, the format and design of the Council ought to be revised to ensure it convenes regularly.

The Philippines Chamber of Commerce and Industry (PCCl) and the government co-host the MSME Resilience Core Group (MSME RCG) that is one of the prominent public-private networks for MSMEs' resilience in the country. While the PCCl's role has been conducive to engaging private-sector actors in building MSMEs' resilience, some stakeholders interviewed suggested that there is scope for strengthening the engagement with local chambers of commerce to promote training for MSMEs on business continuity management at the local level. This engagement could help PCCI reach out to an even wider range of communities.

In Senegal, large companies, many of which are French multinational companies such as Orange, Free, Société Générale and BNP Paribas, are engaged in CSR programmes that support MSMEs in their respective sectors (e.g. climate information push alert text messaging systems for telecommunications companies; climate resilient credit lines for women in the banking sector). While entities such as RSE Sénégal and development co-operation providers such as UN Women try to align CSR activities with MSME resilience efforts, large companies are not yet co-ordinating their activities to promote MSME climate resilience.

Even if MSMEs are formally invited to policy-making processes on climate resilience, governments may still need to review the process and improve its functions and accessibility for private-sector actors. Some stakeholders in the Philippines have mentioned that although the private sector is eligible to participate in meetings of Local Disaster Risk Reduction and Management Councils ${ }^{2}$, many MSMEs consider the accreditation process for the participation unduly complex and burdensome. Streamlining the accreditation process could facilitate greater participation of those businesses in the meetings, which could foster exchange between the Councils and MSMEs on their circumstances and needs. In Senegal, some private-sector actors participate in meetings of COMNACC. Yet, some interviewees noted that their participation was ad hoc, if not symbolic, limiting meaningful exchanges of information and opinions. Further, in Senegal and Guatemala, processes of public participation exist but are not maintained over time, nor are they designed to discuss private-sector perspectives (e.g. how to make the business case for climate resilience).

Right incentives for MSMEs to participate in such policy dialogues and public consultations on climate resilience are needed, given the time and financial costs of participation. Stakeholder interviews highlighted some examples of the incentives. For instance, such platforms could provide participants with information on how to access public financial and technical support available for them to work on resilience. Trainings on practical methodologies for adjusting business operations in response to

${ }^{22}$ For further information on the Local Disaster Risk Reduction and Management Councils, see the Philippines case study or Chapter 6 of (OECD, 2020[39]) 
climate and disaster risks could also be a good reason for businesses to be engaged in such platforms, while networking opportunities could also be of interest to certain MSMEs.

Governments can leverage the presence of local offices of national-level ministries and agencies, and non-governmental networks at the local level, to facilitate vertical and horizontal collaboration for strengthening MSMEs' climate resilience (Dazé, Price-Kelly and Rass, 2016 [38]; OECD, 2020[39]). In the Philippines, the Climate Change Committee (responsible for climate policies) and the Department of Trade and Industry (responsible for MSME sector development) have limited presence and resources at the local government level. They could deepen the engagement with local offices of, for instance, the Department of the Interior and Local Government and the Department of Agriculture to facilitate vertical co-ordination and better support from local government units. Such vertical collaboration could also improve flows of information across levels of governance, facilitating dialogues, uncovering good business practices and sharing lessons learnt. Nevertheless, the feasibility of this approach depends on financial and human capacities in the local offices, for which financial and technical support of development cooperation could be effectively provided. In Guatemala, while national-level ministries ought to have locallevel staff to support ministerial action there, civil servants are often not deployed, or when deployed, are limited in number and typically overwhelmed with multiple tasks. Similar situations were also observed in the Philippines and Senegal.

Greater co-ordination of interventions among development co-operation providers can improve efficiency of their support to MSMEs on climate resilience, while minimising the risk of policy misalignment. In the case study countries, these policy domains include development interventions in particular sectors (e.g. fisheries, agriculture and tourism), MSMEs competitiveness, and climate change and disaster risk reduction activities. In the Philippines, there is already a good level of co-ordination among development co-operation providers and a review process on their interventions conducted by the National Economic Planning Authority. Nevertheless, even for the same sector in the same community (e.g. tourism), different development co-operation providers have different objectives, time frames and interests of their respective interventions. While such differences are inevitable to a certain extent, they often make it challenging for the local government to co-ordinate different support activities. 


\section{Box 1.6. Co-ordination mechanisms for coherent development co-operation efforts}

The Philippines' Climate Change Commission had formerly organised formal donor co-ordination meetings, but the Commission hosts rather informal, ad-hoc meetings as of today. While there is already a good level of donor co-ordination, it could still be worth re-establishing a formal co-ordination meeting among development co-operation providers on climate issues. In doing so, the focus of the coordination meetings could be expanded to include issues around climate resilience of MSMEs.

In Guatemala, co-ordination among development co-operation providers is lacking, which often results in duplication of efforts or the implementation of projects that are not aligned with domestic priorities and needs (e.g. at some point over 20 potato production projects were implemented in one part of the country, when the national stable product is corn; duplication in projects, including the financing of the same activity from different sources, is commonplace in the country).

In Senegal, co-ordination was less frequently mentioned as a key challenge for the government, as most provider activities have to go through the Ministry of Planning, which determines the domestic actor(s) to engage in the implementation of a given project. Co-ordination and coherence across donor activities in the country nevertheless remains a challenge. For instance, while a donor agency promotes initiatives in climate resilience in Senegal, the same agency has a work programme, run by another team, on private-sector capacities in export promotion which did not reflect issues around climate risks.

\section{Enabling policies for private-sector engagement}

Governments need to ensure that climate resilience considerations are reflected in both nationallevel development strategies and local- and sector-level policies and programmes, including those targeting MSMEs' competitiveness. Climate change adaptation, disaster risk reduction and the development of MSMEs are all central priorities for the Philippines' development policy agenda. However, progress on implementation of these policies varies markedly among different local government units, often dependent on their leaders' awareness of climate risks and willingness to allocate resources. In Senegal, the country's overarching policy framework, the Plan Sénégal Émergent (PSE), also explicitly recognises climate change issues as a national priority. While such recognition is encouraging, there is scope for mainstreaming climate resilience into thematic and sectoral policies in the country. For instance, the country's on-going effort to update various policy frameworks (e.g. on youth employment, women's economic empowerment or food security) can offer opportunities to incorporate climate resilience considerations as well. Guatemala's development policy agenda, called Catún32, has led to the country passing one of the first climate change laws worldwide. However, many of the by-laws and sector codes that could help operationalise the law on climate resilience are still to be developed or updated (e.g. on water, infrastructure development, waste management).

Governments can further integrate climate resilience considerations into the design and implementation of their economic instruments ${ }^{3}$ that can affect MSMEs' business decision making. Policies that incentivise or require MSMEs to implement action on climate resilience can take various forms. For example, the inclusion of flood resilience in building codes, the integration of climate resilience aspects into appraisal processes of public investment programmes, or fiscal support for drought-resilient crops (OECD, 2020 $\left.{ }_{[39]}\right)$. Some policies may not directly target climate resilience, but can still significantly contribute to reducing vulnerability or exposure of MSMEs to climate hazards. Such policies can be related

\footnotetext{
${ }^{3}$ Economic instruments are fiscal and other economic incentives and disincentives to incorporate environmental costs and benefits into the budgets of households and enterprises (OECD, 2003[87]).
} 
to, for instance, business continuity management plans, reforms of agricultural subsidies or water tariffs, or the formalisation of informal businesses.

The case study countries already have a range of existing policy instruments that can offer opportunities to integrate climate resilience considerations. Development co-operation can also help the governments seize such opportunities through technical assistance. In the Philippines, for instance, development of business continuity plans has already been promoted through various public and private initiatives, helping businesses better prepare for disruptions after disasters. Yet, introducing policy incentives for businesses to consider long-term climate risks within their business operations is still at an early stage. In Guatemala, legislative codes for many policy domains are outdated or do not exist. Water Code was mentioned by interviewed stakeholders as an example of such legislative codes. They also highlighted that, if designed properly, the Water Code would provide a great potential to improve smallholder farmers' access to affordable water and their resilience to drought risks through more effective water resource management.

Governments can pursue synergies between climate change adaptation and mitigation. This is not unique to the context of MSMEs' climate resilience. It would nevertheless be worth mentioning that experience with mitigation policies in the case study countries can present a good practice example to design policies that also encourage MSMEs to invest in action on climate resilience. A finding in the Senegal study indicates that the recent changes in policies, driven by concerns over energy security, have improved the financial attractiveness of renewable energy and energy efficiency technologies in the country. In Guatemala, a similar finding pointed to the fact that most of the climate-related progress made in the country also pertains to climate change mitigation. Increasing numbers of MSMEs in both countries have been exposed to climate change mitigation technologies and have understood the benefits of investing in these technologies. Some interviewees also recognised potential adaptation benefits of certain mitigation investments, such as solar-powered water pumps (for easier and more cost-effective water access) or drying stations for fish or mangoes (for economic diversification of farmers' or fisherfolks). In both countries, the experience in investing in climate mitigation has helped demystify the concept of climate change as an area where MSMEs cannot generate economic benefits.

Where relevant, governments can also integrate climate resilience considerations into their efforts to formalise private-sector economic units, often with support from development co-operation. Informal MSMEs are widespread in developing countries, including in the three case studies. In most cases, such businesses are operating in the informal sector for subsistence reasons, rather than for economic opportunities. Providing the informal sector with social protection measures in case of disasters remains crucial for the governments. At the same time, lifting businesses from informality can improve their access to broader policy support and trainings for climate resilience building, and formal financial services.

A combination of social protection and formalisation efforts can in turn help those businesses alleviate their pressure to survive, and free up their resources to invest in equipment and other assets to make their businesses more resilient and also more productive. For instance, the Banque Agricole in Senegal provides loans to MSMEs that are organised around producer organisations, agricultural co-operatives, or groups of micro or individual businesses. These stakeholders sign collective, communal contracts with the Banque Agricole for loans and insurance products. This form of contracts can reduce transaction costs and increase access to credits and financial products. Stakeholders interviewed noted that by contracting this insurance, farmers were able to take risks and invest, including in ways that enhanced their resilience (e.g. diversifying produce, improving storage facilities, reaching new markets). Many farmers in the informal sector, on the contrary, are excluded from this system, as they are often not part of any of such producer organisations.

Development co-operation providers can support governments in identifying entry points to incorporate climate resilience into sectoral and MSME-related policies by bringing expertise, tools and resources, including financial support. Many governments face budget constraints, thus are often 
not able to allocate funding to pilot new policy measures. Development co-operation providers have a role to play in demonstrating cost effectiveness of new initiatives or approaches, and are already supporting pilots on approaches to enhancing climate resilience of MSMEs. This, in turn, can help governments understand the benefits and challenges of the piloted policy measures and examine their socio-economic, political and fiscal implications. All the three case studies revealed a number of examples, some of which are presented below, while Box 1.7 provides examples beyond case study countries:

- The government of Guatemala has traditionally been focused on climate change mitigation policies, and it has been the role of development co-operation providers to push for adaptation policies. Development co-operation providers also use the good practices and lessons learnt from other countries in the Central American region and elsewhere to push for climate change adaptation policy frameworks in Guatemala, including those related to MSMEs.

- In the Philippines, the government prepared a Roadmap for Strengthening the Disaster-Resilience of SMEs in collaboration with the iPrepare Business Facility for engaging the private sector. This facility is a joint initiative by the Asian Disaster Preparedness Center (ADPC), the Asian Development Bank (ADB) and GIZ, within the framework of the Global Initiative on Disaster Risk Management (GIDRM). For another example, the Department of Tourism, with support of the World Bank Group and the ADB, launched an initiative called the Transforming Communities towards Resilient, Inclusive and Sustainable Tourism (TouRIST). Among the objectives of the TouRIST project is to develop the capacity of local stakeholders to protect and conserve healthy oceans and rehabilitate key biodiversity-based tourism sites in order to promote sustainable tourism in the country (OECD, 2020[39]).

- The Government of Senegal has been working with UNDP and USAID to develop the country's national adaptation plan. France through its AdaptAction programme has supported the integration of environmental and climate-related issues in some of the Senegalese institutions that support MSMEs. Other examples are the Adaptation for Smallholder Agriculture Programme (ASAP) by the International Fund for Agricultural Development (IFAD) to support the Ministry of Agriculture in capturing international climate finance; USAID's long-standing initiative with the Ministry of Fisheries that dealt with climate change adaptation and climate resilience in the fishery sector; or GIZ's Private Sector Adaptation to Climate Change (PSACC) programme for MSMEs to help them assess climate risks and opportunities to develop tailored adaptation strategies. All of these projects and activities have one thing in common, namely that they were helping the government of Senegal consider climate resilience issues, which could have not been integrated otherwise. 


\section{Box 1.7. Further examples of development co-operation enabling policies on climate resilience}

Canada, Germany, Austria and the United States support the NAP Global Network that has provided technical assistance in over 40 countries for development and implementation of their NAPs through technical assistance, peer-learning activities and analysis, communication, and knowledge products. One area of support is on private-sector engagement in climate adaptation (NAP Global Network, n.d.[40]). The NAP Global Network and GIZ published guidance on private sector engagement in national adaptation planning (Crawford and Church, 2019[10] ) and developed a toolkit on this topic in partnership with the UNFCCC Adaptation Committee (Crawford, Church and Ledwell, 2020[9]). The NAP Global Network has also supported the governments of Ghana, Saint Lucia and Viet Nam to develop NAP private sector engagement strategies (Government of Viet Nam, 2020[41]; Government of Ghana, 2019[42]; Government of Saint Lucia, 2020[43]).

The UNDP and the government of Maldives also conducted a study that compares economic and environmental benefits of policy options in support of climate resilience, which also aims to help the private sector better understand the implication of policy changes for their businesses. Germany collaborated with Ghana's government to implement an integrated climate risk management strategy to protect smallholders and commercial agribusinesses against financial risks associated with extreme events (MCII and GIZ, 2019 $\left.{ }_{[44]}\right)$. Peru developed a comprehensive strategy for financial protection against disasters in co-operation with the World Bank, Switzerland and other development co-operation providers (OECD, 2020[39]).

USAID has supported the Bicol Agri Water Project (BAWP) in the Philippines (USAID, 2017 $7_{[45]}$ ). Under the project, seasonal climate forecasts were disseminated among the rice farmers provided them with good farming actions (on planting, irrigation, harvesting) given the climate outlook within the next three to six months. Such forecasts enabled MSMEs to better understand, for instance, whether to invest in setting up a storage facility in an area less prone to flooding.

\section{Data and information}

Greater collaboration between public, private and research institutions offer a great opportunity to improve quality and granularity of climate and weather data and information, and MSMEs' access to them. The three case studies suggest that no one single institution can meet the demand of all MSMEs for climate and weather data and information, whether it is a national meteorological office, a large private company, a research institute, or a development co-operation provider. The case studies also suggest that there is in general limited economic incentive for private-sector actors to provide climate and weather data and information for free, given their public goods nature. The governments of the case study countries, on the other hand, also face significant budget constraints to developing and disseminating sufficient numbers of weather, water and climate observations. Deeper and broader collaboration among governments, research institutions, development co-operation providers and the private sector has a great potential to more efficiently collect data, and generate and disseminate information on hazards and vulnerabilities. It is also important to make sure that such data and information are readily available and accessible. The format of information may also need to be adjusted for users, depending on their local languages and literacy levels.

Governments, especially national meteorological offices, can enhance their engagement with users of information in the private sector so that climate data and information meet the users' needs. Early and sustained engagements with MSMEs as potential users can help ensure that the climate data and information provided is decision-relevant, compatible with the capacities of the intended MSMEs in understanding climate risks, and, in turn, build their confidence in using such information and data 
(Street, 2019[46]; Weaver et al., 2017[30]; Butler et al., 2015 $5_{[47]}$ ). For example, several interviewees mentioned that farmers need information that helps them understand the implications of a particular weather event (e.g. in terms of when to sow seeds or harvest). MSME owners with limited literacy may want voice messages or call options, while those not speaking the official language fluently may need information in a local language. For instance, Senegal has several national languages, but most climate and weather information, especially by private-sector actors, tends to be delivered in French.

To enhance the engagement, some adjustments may need to be made to the mandates or operational rules of government bodies in charge of producing weather and climate data. For instance, the current mandate of the Guatemalan meteorological office (INSIVUMEH) does not require the institution to examine in detail what the users' needs are, hence not incentivise its staff to analyse the usefulness of data they produce. Limited budget available to INSIVUMEH has also constrained human capacity to do such analysis. The Senegalese meteorological office, ANACIM, presides the Inter-ministerial Council on Climate Services that meets every ten days, but this group does not include the ministries on MSMEs, nor representatives from the private sector (WMO, 2018[48]).

Governments and development co-operation providers can pay particular attention to the collection of gender and age-disaggregated data (Crawford, Church and Ledwell, 2020[9]). The Philippines, for instance, has a guidebook for local government units on climate and disaster risk assessment. A review of the guidebook by $\mathrm{GIZ}$ shows that while the coverage of this guidebook is comprehensive, there is still room for improvement in mainstreaming gender and social inclusion aspects into the methodologies to climate and disaster risk assessments $\left(\mathrm{GIZ}, 2020_{[49]}\right)$. It also concludes that collecting population data by gender would relatively be easy, hence should be promoted to the quality of the risk assessments (GIZ, 2020[49]).

Development co-operation can support governments' role in enhancing data and information that are relevant to MSMEs' decision making on climate resilience activities. Whether and how MSMEs make such decisions depends on the availability and quality of, and access to, multiple types of information, including those listed below. At the same time, governments and development co-operation can also support MSMEs in developing capacities to use such data and information to conduct climate risk assessments (see some examples of tools in Box 1.8)

- Climate data and information, which enhance MSMEs' and related actors' knowledge and understanding about the potential impacts of climate change and/or climate variability,

- Information on MSMEs themselves (e.g. their locations, business operations and assets) and socio-economic contexts of their businesses, and

- Information on available options for measures to build MSMEs' climate resilience, and practical approaches and financial solutions for the measures (e.g. climate change adaptation, disaster risk reduction, risk transfer instruments).

Development co-operation and the government can also further invest in medium- and long-term climate projections to help MSMEs better understand potential long-term impacts of climate change on their business opportunities and livelihoods. For example, such projections can help MSMEs in agriculture sector and local governments to consider how current crop yields may be affected, or which marketable crops and agriculture technologies are likely to be better suited to future climate conditions. This way, farmers and agriculture associations can start exploring opportunities accordingly. Such analysis would also include market research to ensure that what can be grown has a market, or that new markets can be cultivated.

Where appropriate, governments with support from development co-operation providers, can establish, maintain and improve a centralised platform that facilitates MSME access to climate data and information. In Senegal, stakeholders interviewed mentioned insufficient granularity and userfriendliness of information for MSMEs in the agriculture or fisheries sectors. ANACIM with support of 
development co-operation providers, has started providing targeted climate information and data directly to MSMEs, often joining forces with the governmental institutions that support MSME sector development. The GeoRiskPH initiative, launched in 2019 in the Philippines, can also set a model for the national government, local government units and academia to collaborate on data collection and information sharing, which may better inform MSMEs' decision-making on management of climate and disaster risks.

\section{Box 1.8. Tools in support of MSMEs' decision making on climate resilience}

The UN Office for Disaster Risk Reduction (UNDRR) has launched a Quick Risk Estimation (QRE) Tool to help MSMEs, including those in the informal sector, to understand their exposure and vulnerability to disaster risks, especially in the context of the on-going COVID-19 pandemic. The QRE Tool aims to strengthen those businesses' resilience and continuity planning in light of the multiple risks that businesses face in today's environment of climate change and COVID-19. The QRE Tool includes an interactive questionnaire that produces a dashboard on estimated MSME general risk levels. The results take into consideration business size, type, and geographic location, along with a number of other factors. [See (UNDRR, n.d.[50]) for further information.]

GIZ has developed a Climate Expert tool to build the capacity of companies to analyse climate risks and opportunities and how to respond to the development of climate resilience strategies. Several companies around the world have used the 4-Step Climate Expert Approach to identify climate change impacts and measures to strengthen climate resilience. Those companies have assessed risks, opportunities and measures to develop an adaptation strategy that fits their situation and priorities. [See (GIZ, n.d.[51]) for further information.]

In Sri Lanka, UNEP DTU Partnership, in collaboration with the Asian Disaster Preparedness Center, the Ceylon Chamber of Commerce and MPEnsystems, has been developing a smartphone App for supporting business resilience as a toolkit to support in-depth analysis of the disaster impacts and related costs incurred by businesses, and their behaviours and preferences. The tool is being piloted in selected flood-prone case areas with built-in features that aim to help MSMEs understand how flooding impacts their specific operations and how they can reduce their risks by identifying and investing in the most suitable adaptation measures. As of 2020 , the prototype toolkit is made available through a smartphone app, available for Android and iPhones. [See (UNEP DTU, 2018[52]) for further information].

Governments and development co-operation providers can also enhance their engagement with universities and research institutions to develop MSMEs' capabilities in conducting climate risk assessments and generating context-specific information on their vulnerabilities. Several universities and research institutions have already been working to provide climate-related data and information, and support assessments of climate risks to MSMEs in the case studies (e.g. the Resilience Institute and the Institute for Small-Scale Industries, both under the University of the Philippines, the National Institute for Agricultural Research of Senegal, or the Universidad del Valle de Guatemala). Enhanced capacities of academic and research institutions, especially at the local level, can also improve the availability of information on local MSMEs' operations, location and assets, as well as the socioeconomic circumstances of MSMEs. Such (non-climate) information can help governments, development co-operation and MSMEs assess the underlying drivers for the vulnerability of businesses in question. Context-specific information can complement climate data and information provided by national-level meteorological offices and large enterprises, enabling to conduct a more granular assessment of climate risks and vulnerability of MSMEs (Ford et al., 2018[31]).

Governments and development co-operation providers benefit from strengthening channels through which they can obtain information from local private-sector actors and other stakeholders, 
such as civil society organisations. Such information channels can promote participatory approaches that enable governments and development co-operation providers to complement scientific data with Indigenous, local and traditional knowledge, when planning policy measures to enhance climate resilience of MSMEs (UNESCO, 2017[53]). Such participatory approaches may also improve local actors' buy-in for the policy measures. Stakeholders in the Philippines and Senegal pointed out that not all local-level actors would be receptive to adopting measures proposed by governments or development co-operation providers, especially when these measures were not considered consistent with the actors' own experience of past weather events or traditional and cultural norms embedded in the communities.

Governments and development co-operation providers could promote awareness raising of the need for MSMEs to strengthen climate resilience by using plain words that are clear and comprehensible to businesses and households (Crishna Morgado and Lasfargues, 2017[13]). Policy dialogues with MSMEs need to use terminology and concepts that are familiar to the private sector (e.g. terms used in business continuity management, property and asset management, logistics and supply chain management, among others). The complex terminologies of climate science and policy-making are unlikely to gain sufficient traction with MSMEs and local-level stakeholders, compared to messaging around risks, losses and returns associated with their businesses (Schaer and Kuruppu, 2018[8]; Crawford, Church and Ledwell, 2020[9]).

Governments and development co-operation providers can design and implement monitoring and evaluation processes in ways that facilitate continuous learning, with the aim to improve approaches to strengthening the climate resilience of MSMEs over time. Greater engagement with the private sector may help public-sector actors define indicators for monitoring and evaluation, collect relevant data and information, and assess outcomes and impacts of interventions by governments or development co-operation providers. A wide variety of mechanisms can also be employed to collect quantitative or qualitative information, including community surveys, satellite imagery, geographic information systems, and document reviews (Crawford, Church and Ledwell, 2020[9]).

Information obtained from monitoring and evaluation processes can inform peer-learning and policy dialogues between public and private sectors, development co-operation providers and civil society so that they can exchange good practices and lessons learnt. For example, the Monitoring and Evaluation Report of the Philippine National Climate Change Action Plan 2011-2016 provides extensive insights into achievements and remaining challenges regarding the private-sector engagement in climate action in the country (CCC, 2019 $\left.{ }_{[54]}\right)$. However, neither Senegal nor Guatemala have such a framework, which can be an area where development co-operation providers could support. When there is information about evaluation results in the two countries, it tends to be very crude. For instance some projects by development agencies are evaluated, but it is unclear how useful this is for Senegal; some Senegalese public institutions evaluate their interventions, but the indicators used (e.g. number of conferences organised at regional level) may not deliver information on which to base learnings.

\section{Finance for strengthening MSMEs' climate resilience}

Governments can use various financial instruments to improve risk-return profiles of MSMEs' investment in support of climate resilience, while development co-operation providers can also support such instruments. These fiscal incentives and development finance interventions can include grants, tax breaks, risk guarantees and government procurement contracts. These may help to create demand for climate-resilient goods and services (Crawford, Church and Ledwell, 2020[9]). National development banks are also important funding entities to provide such financial solutions to MSMEs that are willing to purchase equipment or invest in production assets in support of climate resilience. Table 1.3 provides examples of financial instruments in the Philippines for an illustrative purpose. 
Table 1.3. Examples of financial instruments in support of climate resilience in the Philippines

\begin{tabular}{|c|c|c|}
\hline Entity & Name of the product & Product details \\
\hline \multirow[t]{2}{*}{$\begin{array}{l}\text { Department of Agriculture: } \\
\text { Agricultural Credit Policy Council } \\
\text { (DA-ACPC) }\end{array}$} & $\begin{array}{l}\text { Survival and Recovery } \\
\text { Assistance }\end{array}$ & $\begin{array}{l}\text { Provide immediate relief to small farmers and fisher folk } \\
\text { in calamity-affected areas to rehabilitate or regain } \\
\text { livelihood activities }\end{array}$ \\
\hline & $\begin{array}{l}\text { Climate Change Adaptation Financing Program } \\
\text { (CCAFP) }\end{array}$ & $\begin{array}{l}\text { Provides loans for climate-resilient farming and fishing } \\
\text { practices, technologies and measures, as a focal } \\
\text { component of an integrated package of support services } \\
\text { for farmers and fisher folk that include climate advisory, } \\
\text { credit guarantee, insurance, market linkage, among } \\
\text { others }\end{array}$ \\
\hline \multirow{3}{*}{$\begin{array}{l}\text { Landbank of the Philippines: LBP } \\
\text { CaReS (Calamity Rehabilitation } \\
\text { Support Program) }\end{array}$} & Rehabilitation thru Loan Restructuring & $\begin{array}{l}\text { Additional or new financing; loan take-out from other } \\
\text { financial institutions in case of disasters }\end{array}$ \\
\hline & $\begin{array}{l}\text { Kaagapay sa Negosyo (KNegosyo): Credit } \\
\text { Program for SMEs }\end{array}$ & $\begin{array}{l}\text { To repair existing facilities or purchase new ones after } \\
\text { disasters; to augment working capital requirement }\end{array}$ \\
\hline & $\begin{array}{l}\text { Lingkod Para sa Pabahay (LINGAP) : Credit } \\
\text { Program for Homebuyers }\end{array}$ & $\begin{array}{l}\text { Repair existing housing units or construct or purchase } \\
\text { new ones }\end{array}$ \\
\hline $\begin{array}{l}\text { Development Bank of the } \\
\text { Philippines }\end{array}$ & $\begin{array}{l}\text { Rehabilitation Program for Agriculture and } \\
\text { Industry Responsiveness (REPAIR) }\end{array}$ & $\begin{array}{l}\text { To expedite recovery and rebuilding process of } \\
\text { calamity-stricken areas }\end{array}$ \\
\hline $\begin{array}{l}\text { Bankers Assurance Corporation } \\
\text { (provision of insurance) } \\
\text { Cebuana Lhuillier Insurance } \\
\text { Solutions (distribution) }\end{array}$ & $\begin{array}{l}\text { Negosyo Care: Personal and Property } \\
\text { Insurance specifically designed for MSMEs }\end{array}$ & $\begin{array}{l}\text { Coverage: property insurance, burglary and robbery, } \\
\text { accidental death, permanent disablement and } \\
\text { dismemberment, accident medical reimbursement } \\
\text { (AMR) money, securities, and payroll coverage }\end{array}$ \\
\hline $\begin{array}{l}\text { GIZ-Cebuana Lhuillier-AXA LIFE } \\
\text { Implemented by GIZ } \\
\text { Insured by AXA Philippines } \\
\text { Distributed by: Cebuana Lhuillier } \\
\text { Insurance Solutions }\end{array}$ & MicroBiz Protek Insurance & $\begin{array}{l}\text { Coverage: fire and lightning, typhoon, flood, earthquake } \\
\text { Extended coverage: smoke, falling aircraft, vehicle } \\
\text { impact and explosion } \\
\text { Aims to contribute to the financial stability and literacy of } \\
\text { MSMEs that are vulnerable to natural and man-made } \\
\text { disasters }\end{array}$ \\
\hline
\end{tabular}

Note: The financial products cover climate related as well as non-climate related disasters.

Source: (MSME Resilience Core Group, 2020[55]) MSME Guide to Disaster Resilience, https://www.dti.gov.ph/sdm_downloads/msme-guide-todisaster-resiliencel; (Government of the Philippines, n.d.[56]) Agricultural Credit Policy Council (ACPC), https://acpc.gov.ph/; (CCC, 2019[54]) Executive Brief: The Philippine National Climate Change Action Plan, Monitoring and Evaluation Report 2011-2016, https://climate.gov.ph

Governments and development co-operation providers would benefit from allocating finance to measures that build MSMEs' climate resilience and push other development agendas in a coherent manner. While acknowledging areas that require dedicated funding (e.g. health, social safety nets, humanitarian aid), findings from the case studies highlight the importance of efficiently using scarce public financial resources, be they domestic or external. In the Philippines, budget lines for non-climate policy agendas include those on improvement of agriculture-sector productivity, creation of green jobs and, as in most countries, economic recovery from the COVID-19 pandemic. Integrating climate resilience consideration into public finance for these policy agendas could provide opportunities to more efficiently and coherently enhance climate resilience and the competitiveness of MSMEs as well as social well-being in the country.

Budget tagging and public expenditure reviews can be effective for governments to understand where finance is allocated and disbursed. Such approaches could also help governments review where opportunities exist to support coherent implementation of policies on climate resilience and those on MSME sector development. Tagging and review exercises can help governments identify entry points for mainstreaming climate resilience of MSMEs into public budgets. The government of the Philippines has established an initiative on Climate Change Expenditure Tagging (CCET) at the national and local level that came into effect in 2015 (OECD, 2020[39]).

Governments, possibly through their national development banks and with development cooperation providers, can engage with private-sector financial institutions such as commercial banks and insurance companies to promote MSMEs' action on climate resilience. Affordable loans 
and insurance products available for MSMEs to invest in climate-related goods and services could lead to higher climate resilience of the society as a whole. In the case studies and many other developing countries, however, MSMEs tend to have limited access to credit from private financial institutions, even less so for climate resilience activities [see the case studies as well as, for instance (Schaer and Kuruppu, 2018[8]; Crawford and Church, 2019 $\left[{ }_{[10]}\right]$ ]. Nevertheless, good practices in public and private finance in support of MSMEs' climate resilience are emerging, including in the case studies:

- The Microinsurance Catastrophe Risk Organisation (MiCRO) provides catastrophic index-based insurance products for micro and small enterprises and farmers in Central America, including in Guatemala. MiCRO also partners with local insurance companies. It plans to expand such index-based insurance products to further countries, and has already submitted one for approval in El Salvador. The goal was to reach 250000 people in the region by 2019, but the COVID-19 crisis has delayed this ambition.

- The Land Bank of the Philippines (LANDBANK), a state-owned financial institution, supports MSMEs and local government units to adopt measures for climate-resilient businesses through different funding programmes. They include the Special Adaptation Facility for the Ecosystem and the Climate Resilient Agriculture Program and the Climate Change Resiliency Program (LANDBANK, 2018[57]). The Small Business Corporation (SB Corp), another public financial entity in the Philippines, adopted MSMEfriendly policies (e.g. a longer grace period for interest and principal) within the bank's programme on rehabilitation loans in case of calamity (i.e. Enterprise Rehabilitation Financing). SB Corp also supports its loan applicants through the government's post disaster needs assessment and monthly project inspection of the first year of repayment (Government of Philippines, 2018 ${ }_{[58]}$ ) (See also Box 1.9).

- Some commercial banks in Senegal have provided loans for MSMEs to acquire solar-powered water pumps or domestic biogas systems. These loan programmes do not focus on climate resilience as such, but have potential co-benefit (e.g. solar-powered water pumps could ensure water access in case of disruption to the electricity grid caused by disasters). The experience of operating the programmes can also provide lessons on how the government can further engage with commercial banks in promoting finance for climate action, including that on climate resilience. Further, the Banque Agricole in Senegal provides loans to MSMEs with the condition of purchasing crop insurance.

\section{Box 1.9. Greening financial systems in the Philippines}

The Central Bank of the Philippines and the Bankers Association of the Philippines, in co-operation with IFC and the Green Climate Fund, have launched a programme on "greening of the financial system". Engaging with local financial institutions in the country, the programme plans to carry out local business case studies on the benefits and the risk-return profile of green and sustainable investments. The programme also aims to develop guidelines, guidance and tools for the appraisal and the periodic evaluation of the risks in the light of environmental and social sustainability. Local financial institutions are expected to receive support in capacity development for identifying business opportunities, developing a project pipeline and conducting robust due diligence for climate-related projects.

Source: (GCF, 2019 $\left.{ }_{[59]}\right)$, Strategic Frameworks support for the Philippines through IFC, https://www.greenclimate.fund

Governments can further enhance enabling policies to promote insurance as part of a comprehensive approach to building the climate resilience of MSMEs. Interviews under the case studies have re-confirmed several well-known challenges to uptake of insurance (see also examples in Box 1.10). These include insufficient awareness among MSMEs of the benefits of insurance, management of unmet needs in terms of payouts, limited coverage of marginalised farmers, as well as underserved regions, especially those prone to tropical cyclones and flooding. Legal frameworks also impede the private sector to enter the insurance market. For instance, interviewed stakeholders mentioned that current legal 
frameworks in the Philippines precluded private insurance companies from receiving government subsidies for premiums of their products, which may have blocked insurance companies from entering the market.

Governments, public insurance companies and development co-operation providers can engage with the private insurance sector to pilot new or less disseminated insurance products, such as index-based insurance. In all three case studies, index-based insurance has been introduced in recent years and shows strong potential to strengthen MSMEs' climate resilience. Examples include the following:

- In Senegal, CNAAS (a public-private insurance company) developed index-based insurance to, for instance, cover for a rain deficit. CNAAS uses weather stations and satellite information to monitor indicators that trigger the payouts, departing from its traditional indemnity insurance model. As mentioned, the Banque Agricole covered all of its operations with one of the two types of insurance to manage its clients' credit risks, with a preference for index-based insurance due to its lower costs. This has led to coverage of approximately $10 \%$ of all Senegalese farmers in a few years (notably cotton, peanut, corn and livestock breeders). New insurance tools are being piloted in other sectors (e.g. fisheries with flexible risk transfer options such as insurance-for-assets programmes) and across regions.

- In the Philippines, the ADB has partnered with the Philippine Insurers and Reinsurers Association (PIRA) and the Philippine Crop Insurance Corporation (PCIC) to conduct a study on possible impact of the private sector involvement on an increase in the uptake of agriculture insurance in the country (ADB, 2017[60]). In terms of dissemination, the so-called 'sari-sari' stores, neighbourhood convenience stores found all across the Philippines, are already playing the role in disseminating financial solutions, such as micro-insurance (UNDP and PBE, 2017[61]) (Nielsen, 2014[62] ). Global Affairs Canada has collaborated with the 'sari-sari' stores who were insured by the micro-insurance products (Global Affairs Canada, 2019[63]), while at the same time selling and disseminating them to, for instance, small farmers.

Development co-operation also plays an important role in promoting comprehensive risk management by enhancing governments' and the private sector's understanding of how to select appropriate financial instruments for different types of climate risks. No single financial instrument can address all types of climate risks, leading to the need for governments to efficiently combine different financial instruments for various phases: from preparing for and reducing climate risks, to responding to disasters. These financial solutions include debt instruments for preparation, grants for risk assessment as well as response and recovery, insurance and catastrophe bonds for risk transfer, among others. In the Philippines, for instance, GIZ's Micro Disaster Risk Insurance for Micro, Small, and Medium Enterprises (MicroDRI) project has developed a checklist on disaster risks, one of whose aims is to promote insurance uptake among small businesses (MSME Resilience Core Group, 2020[55]).

\section{Box 1.10. Legal barriers to entrance of private sector companies to the insurance market}

Both public and private insurance companies in the case study countries still face various challenges to establishing and scaling up stable business models of insurance products to manage climate and disaster risks to MSMEs. For instance, legal hurdles often impede the private sector to enter the market. The Philippine Crop Insurance Corporation (PCIC, a public insurance company) covers approximately $10 \%$ of the crop producers and the Philippine Insurers and Reinsurers Association (PIRA) together with $A D B, P C I C$ and other stakeholders have set up a task force to evaluate if the of entry private sector insurance companies to the market can increase the uptake of crop insurance. However, by law PCIC is the only entity that can issue crop insurance. Interviewed stakeholders also mentioned that current legal frameworks preclude the private sector from receiving government subsidies for premium, which may have blocked private sector insurance companies from entering the market. 


\section{Summaries of the case studies on Guatemala, the Philippines and Senegal}

This section provides summaries of three country case studies, namely Guatemala, the Philippines and Senegal. They outline the countries' approaches to engaging the private sector in efforts for climate resilience. These are related to the countries' institutional arrangements, policy frameworks, climate and weather data and information; and finance. The section also examines the role of development co-operation in engaging the private sector in strengthening climate resilience in each case study country. It also provides possible ways forward to enhancing such approaches by the governments and development co-operation providers. 


\subsection{Approaches in Guatemala: Findings and ways forward ${ }^{4}$}

Guatemala is among the ten countries in the world that are most vulnerable to climate change and among the most exposed to natural hazards in the region (WFP, 2020[64] $)$. About one-third of Guatemalans depend on natural resources for their livelihoods, yet the natural resource base is already degraded by overexploitation, deforestation, and slash-and-burn agricultural practices (USAID, 2017[65]). Climate change is further degrading the natural resource base of the country, threatening the long-term development of Guatemala, worsening the condition and livelihoods of the poor and vulnerable, notably indigenous communities.

MSMEs contribute to at least $40 \%$ of Guatemala's GDP and $85 \%$ of employment (World Bank, 2014[66]). The majority of MSMEs in the country operate in the informal sector and in labour-intensive sectors, such as agriculture. Although the country has large monocultures and transformation industries (e.g. palm, sugar, coffee), most economic units are small and informal [about $70 \%$ according to (MINECO, 2015 677 )]. According to Guatemala's second communication to the UNFCCC, those small farmers are the most impacted by climate change, losing on average $55 \%$ of their production during droughts and floods (MARN, 2016[68]).

The significant contribution of MSMEs to the Guatemalan economy, their concentration in the agricultural sector, as well as their vulnerability, calls for enhancing their climate resilience if the country is to ensure a sustainable development pathway. Yet, to date, the capacity of Guatemalan MSMEs to adapt to climate change and cope with damages by disasters remains low. Small businesses often perceive climate change issues as a distant, theoretical urban concept, which is difficult to implement in rural areas or by MSMEs, even when there is interest or a need to do so. MSMEs also lack the necessary tools, resources, capacity and technology to face climate change and variability, as well as to promote good adaptation practices that favour the adjustment of productive systems. When climate-related action took place, it depended on the political forces in government and mainly focused on climate change mitigation.

This subsection summarises findings of the case study that examines how the Guatemalan national government and development co-operation providers collaborate with the private sector to strengthen the resilience of MSMEs to manage negative impacts of climate change and variability. This study considers the institutional arrangements, policy frameworks, data and information, as well as financial mechanisms that support MSMEs in the face of short and long-term climate risks in Guatemala.

\section{Institutional arrangements}

The institutional setup to govern climate change adaptation in Guatemala lacks co-ordination across sectors and levels, and does not extend to the institutions working with the private sector. The Ministry of Environment (MARN), responsible for development and implementation of climate policies, lacks the necessary resources and capacity to co-ordinate efforts by other ministries and governmental agencies, to support them or to engage with the private sector, especially MSMEs, in promoting climate resilience. While a number of climate-related institutions exist in Guatemala, these operate autonomously from the MARN.

While a National Climate Change Council exists, chaired at the highest level by the President of the country, the Council has not met since 2017. The Council is heavily dependent on the views of the political party in power and, despite being open to the private sector, has failed to come up with effective measures to help MSMEs build their resilience or to have climate resilience issues mainstreamed across the work of major ministries. As a result, and despite having a Council, institutional co-ordination for climate-related policies occurs on an ad-hoc basis, also hampered by Guatemala's rigid bureaucratic arrangements. As in

\footnotetext{
${ }^{4}$ A full report of the case study is available on: https://www.oecd.org/development/climate-resilience/
} 
other countries, Guatemala also suffers from high levels of staff turnover at the senior level, thus limiting the continuity of many policies and programmes, and hindering the accumulation of climate-related issues in ministries. Co-ordination, more generally could be strengthened through the overarching national planning authority called SEGEPLAN. Even though the MARN has the lead on climate change issues, SEGEPLAN is the institution that operationalises the government's policies. SEGEPLAN is also better resourced than many other public bodies, including the MARN, but lacks mechanisms to ensure that public plans are implemented adequately, mainly due to lack of resources. Hence, co-ordination, when it exists, is often triggered by donor-funded projects on climate resilience. GIZ's Adáptate programme provides an example of provider support to the SEGEPLAN, with benefits for climate resilience - as GIZ worked closely with SEGEPLAN to develop the digital tool PLANIMUCC to integrate climate-relevant data into the municipal planning process and as a basis for a parametric climate insurance.

Co-ordination across levels of government is also limited, with few ministries having enough capacity at the sub-national level to deliver on climate resilience issues or to support MSMEs' development more generally. Municipalities operate as conveyors of information from the central government, rather than as supporters of MSMEs.

The government of Guatemala, with support of providers of development co-operation, could:

- Consider reorganising the environment and climate-related institutional landscape, by bringing closer together the MARN and the institutions working on protected areas (CONAP), on forestry (INAB) and the meteorological agency (INSIVUMEH), as well as the emergency response network (CONRED). Doing so could help the government ensure more coherent and co-ordinated action on climate resilience.

- Reform the Council to ensure that it can meet more regularly, either at a more technical-level or by ensuring that other senior officials than the President, can call a meeting. Council meetings ought to include the private sector, especially the voices of informal MSMEs, and ensure that climate resilience issues are on the agenda.

- Build awareness among politicians and the society at large on the need to protect and insulate climate resilience issues from party politics, to ensure the continuity and, ideally, incremental improvement of action over time. In this context, the role of academia could be emphasised more strongly, as it fills the current data gaps needed for socio-economic-ecological assessment of climate change impacts and needed climate resilience building measures.

- While capacity and resources are at a shortage in Guatemala overall, some need to be committed at the sub-national level - the level of government to which MSMEs turn to when they need support and look for solutions.

\section{Policy frameworks}

Historically in Guatemala the development of climate policies has focused more on mitigation. More so, in recent times its policy framework has also started reflecting climate resilience issues. The Plan Nacional de Desarrollo K'atun: Nuestra Guatemala 2032 y su Política, defines the policy framework for the country until 2032. The K'atun defined the need to pass a climate change law for the country, which took shape with the Climate Framework Law (MARN, 2013[69]). The Law is implemented through regular National Climate Change Action Plans (PANCC), which ought to help the MARN plan and orient public investments. The PANCC has been updated in 2016 and 2018 and includes climate resilience in a number of sectors, as well as activities for the MSMEs.

The PANCC aims to connect climate action with other legislative frameworks (e.g. National Strategy for Biological Diversity, the Development Strategy for Low Emissions from Deforestation). Yet, it is difficult to track progress on the coherence across policies due to limited co-ordination mechanisms and financing. The PANCC provides a framework for public and private actors to operate, but provides limited means for 
implementation (e.g. specific public financial resources and capacity). The PANCC estimates a $71 \%$ financing gap for it to be implemented and depends on the resources of the private sector and providers of development co-operation for its success (with most of this gap affecting climate resilience activities).

Guatemala is developing a National Adaptation Plan for identified sectors, and the by-laws and codes that could support the execution of the NAP with policy measures on climate resilience at the sector level are still missing. For example, the country has no Water Code, and needs updates to the codes on infrastructure or land use. Development co-operation providers often spearhead climate resilience to the government as an important policy agenda. Against this background, the government of Guatemala, with support of providers of development co-operation, could:

- Ensure that the capacity and resources devoted to the implementation of existing climate resilience legislation, such as the activities from providers in this area, is beefed up and sustained over time. This would avoid that most action is concentrated at the normative stage (e.g. development of laws and regulations, strategies and plans), with limited implementation or enforcement.

- Ensure that progress in the implementation of climate-related policies under the PANCC can be monitored and then be evaluated, which would help Guatemalan stakeholders learn from its own experiences, help identify and disseminate good practices, and promote a communication plan on what is working well in the country.

- In addition, additional, specific climate resilience regulations are needed to incentivise MSMEs to change their behaviours. Other regulatory frameworks that can support climate resilience, such as the Water Code, also need to be developed, and better connected to ensure synergies and be clear as to what the priorities are, given limited resources and capacities.

\section{Climate and weather data and information}

The national meteorological institute, the INSIVUMEH, lacks sufficient capacity and resources to generate and deliver climate and weather data and information to adequately help MSMEs foster their climate resilience (e.g. to compile real-time data, carry out evaluations of use and relevance of data compiled). Housed under the Ministry of Communications, the INSIVUMEH suffers from frequent leadership changes, limited climate expertise, a restricted mandate, capacity and budgetary shortages. Several interviewees noted that the INSIVUMEH could strengthen the institutional linkages with the MARN, or could potentially be housed under the MARN with a revamped, more ambitious mandate and resources.

Guatemala collects a host of climate-related and socio-economic information, which could help improve the climate resilience of MSMEs, directly and indirectly. While this information is often spread across different authorities, it may not always be comparable and is difficult for users to access. This situation prevents the government, development co-operation providers and the private sector itself from understanding the country's climate vulnerability and exposure, as well as areas where to focus limited resources and capacities. Some stakeholders interviewed noted that the current set up, in fact, creates confusions among the users of public data.

The private sector also generates useful data and information and fills some of the gaps left by the INSIVUMEH and other public authorities. For example, the Sugar Industry Association has created the Climate Change Institute that has its own meteorological stations, gathering climate-relevant data for farmers in this sector. To continue improving climate data and information for the benefit of MSMEs, the government of Guatemala, with support from providers of development co-operation, could:

- Ensure more capacity and resources are dedicated to the INSIVUMEH, both through the regular budget and through collaboration with providers of development co-operation. Greater investment in the INSIVUMEH could not only promote data collection and information generation, but also widen and deepen its engagement with public and private end users. 
- Promote the reform suggested by domestic stakeholders by which the INSIVUMEH is more closely associated to the MARN on climate-related issues. Expanding the mandate of the INSIVUMEH, aligned with the vision of the MARN, could help in this endeavour.

- SEGEPLAN, the country's central co-ordination unit, and the MARN could develop a platform that would host weather and climate information, produced by INSIVUMEH, research institutes, academia and the private sector, and enable the access to such information for policy and decisionmaking, including to build the climate resilience of MSMEs.

\section{Finance}

The allocation of public resources to institutions and policies that support climate resilience is limited, which is in line with the overall public sector capacity and financial constraints in Guatemala. The country has a small public sector [ranking $112^{\text {th }}$ out of 132 countries; (World Bank, 2020[70])], with low tax and public investment levels. As such, some public institutions have developed programmes and plans to promote climate resilience, for instance the public climate change fund (FONCC) and land fund (FONTIERRAS). The resources allocated are however small, as is the capacity to implement measures, notably at the regional level. Implementing the green fiscal policy devised by the MINFIN and MARN could help raise funds for climate resilience, as it promotes the adoption of technologies that could help with building resilience. Notwithstanding, this context is currently exacerbated by the COVID-19 crisis, which has led to delays in the disbursement of, inter alia, climate-related funds that could help build the resilience of MSMEs.

Guatemala thus mainly relies on development finance and private sector investments to push for MSME climate resilience - which is in line with the expectation from the PANCC (that estimated $71 \%$ of the climate change needs in the country needed to come from beyond public resources). The private sector is increasingly building its resilience to climate and weather- related hazards. Chambers of commerce, for example, have been engaging in climate resilience and supporting MSMEs with information, technology access and capacity building, usually those that are well organised and operate in the formal sector.

Export-oriented sectors (e.g. coffee, sugar, cocoa, cement) are ensuring that MSMEs, both downstream and upstream of their supply chain, are resilient to climate change hazards. Commercial banks are also providing green loans (e.g. Agromercantil, Banrural, Banco Industrial), albeit mainly focused on climate change mitigation - but nonetheless helping raise awareness on climate change issues more broadly. The insurance sector, in turn, is gradually expanding in the country, notably among farmers in sectors that are organised.

Providers of development co-operation have been implementing several projects to strengthen the resilience of MSMEs, notably in vulnerable sectors such as agriculture or fisheries, and in remote areas. However, the support provided by development co-operation has so far tended to focus on the formulation of policies, which is important in itself but remains limited when it comes to actual implementation of the policy measures. To further mobilise finance for the implementation of measures to support the climate resilience of MSMEs, the government of Guatemala, with support from providers of development cooperation, could:

- Ensure appropriate public funds are devoted to climate change issues, notably climate resilience, commensurate with the high levels of vulnerability of the country.

- Implement the existing green fiscal policy (e.g. with green taxes), promoting public-private partnerships, or co-ordinating investments with the private sector and providers of development co-operation, as well as a better appropriation of resources for the FONCC and FONTIERRAS.

- Private sector activities for the supply chain risk management are well-organised, and increasingly so, in export-oriented sectors. These are helping raise awareness on climate risks among MSMEs, e.g. on the need to contract insurance or on methods and solutions to increase competitiveness 
that invest in risk reduction. Such experiences could be shared across MSMEs in other sectors e.g. through a dialogue that could also help leverage funding and blend public, private and development resources.

\section{The role of development co-operation providers}

Providers of development co-operation have been investing in climate resilience for a long time in Guatemala. Over the period between 2012 and 2018, bilateral and multilateral development co-operation providers committed USD 46.5 million in official development assistance on average per year to climate change adaptation in Guatemala, according to OECD statistics (OECD, 2020[71]). Development cooperation providers have been driving most action on climate resilience in Guatemala in all areas reviewed in this report, namely: supporting the development of the institutional setting, policy frameworks, the country's financial system, as well as weather and climate data and information. Notwithstanding this comprehensive support, the stakeholder interviews revealed that a greater collaboration between providers, MSMEs and the government in Guatemala could be achieved. Below shows possible approaches that development co-operation providers could take to further support MSMEs in strengthening their climate resilience:

- Development co-operation providers could promote further coherence across their interventions, either through the G13 group of 13 providers or with additional EU joint programming, as some of the work analysed in this report showed misalignment in provider portfolios with climate resilience issues (e.g. providers promoting agricultural outputs that may not be endemic to Guatemala).

- Development co-operation providers could ensure a greater impact of their interventions, notably by supporting the government with the mainstreaming of climate resilience considerations into the country's national priorities, better co-ordination among providers, and funding activities beyond technical assistance and capacity building (e.g. for actions that are highlighted in the PANCC or funding concrete activities in the sectors highlighted in the NAP).

- Government actors need to find ways to operate more effectively with the provider community, ensuring that the government commits to implementing actions after projects are finalised, helping build bridges with the local level and with MSMEs, as well as increasing the absorptive capacity of development finance. 


\subsection{Approaches in the Philippines: Findings and ways forward ${ }^{5}$}

Making the private sector, especially micro, small and medium enterprises (MSMEs), resilient to external shocks has significant implications for economic growth in the Republic of the Philippines (the Philippines) where $99 \%$ of the total registered businesses are MSMEs (MSMED Council, 2018[72]). Natural hazards and climate change are among the greatest threats to businesses and households in the country. The Philippines has been hit by a number of typhoons and other disasters every year and highly exposed to the negative impacts of climate change, such as sea level rise.

Climate change adaptation, disaster risk reduction and management (DRRM) and the development of the MSME sector are all central priorities for the Philippines' development agenda. The government has made great strides in developing various institutional arrangements and policies to take these three policy agendas forward. Many actors from the private sector, large enterprises in particular, are also co-leading initiatives to build business resilience, often in partnership with the public sector, while an increasing number of MSMEs themselves are becoming aware of the climate risks to their business operations.

This subsection summarises findings of the case study that examines various approaches that the public and private sectors in the Philippines are taking to strengthen the resilience of MSMEs to climate risks. Despite various commitments and initiatives by the public and private sectors relevant to the resilience of MSMEs in the country, a range of assessments have highlighted the challenges to implement concrete measures on the ground [e.g. (CCC, 2019 $9_{[54]}$; HLURB, n.d. [73]; iPrepare Business facility, 2017[74]; OECD, $\left.2020_{[39]}\right]$ ]. Building on those challenges, this study focuses on opportunities for further improvement in the following areas: institutional arrangements; development and implementation of policies; and enhancement of and access to enabling factors such as information, finance and capacity development. The study also examines the role of development co-operation in helping countries seize such opportunities.

\section{Institutional arrangements}

Institutional arrangements for strengthening MSMEs' climate resilience in the Philippines are characterised by multi-sectoral networks. These create an "ecosystem" of top-down and bottom-up institutional arrangements and initiatives by various public and private sector actors as well as academia, civil society organisations and religious institutions (e.g. church groups). For instance, the MSME Resilience Core Group is one of the most prominent public-private networks, which develops national-level strategies for MSMEs' resilience. Another public-private network is the National Resilience Council, which supports science- and technology-based capacity development at the local level, complementing the strategyfocused activities of the Resilience Core Group (NRC, 2018[75]). There are also government bodies that are responsible for each of the three policy areas: the Department of Trade and Industry (for MSME development), the National Disaster Risk Reduction and Management Council (for DRRM) and the Climate Change Commission (for climate change adaptation) (ADPC and DTI, 2016[76]; OECD, 2020[39]).

Businesses of many MSMEs are embedded within the communities where they operate. The specific climate risks and vulnerability of each community therefore highlight the importance of local-level institutions and networks to plan and implement concrete measures for building climate resilience of MSMEs, which fit local needs and capacities. These institutions include the local government units (LGUs), local chambers of commerce, community-level business associations, civil society organisations and local research institutions. State universities and colleges could also support local businesses and LGUs in capacity development for climate resilience (e.g. by serving as an agriculture extension school).

\footnotetext{
${ }^{5} \mathrm{~A}$ full report of the case study is available on: https://www.oecd.org/development/climate-resilience/
} 
Interviews conducted for this study have suggested that, while many public- and private-sector actors recognise the importance of local-level action, there remains scope for improving ways in which local MSMEs can be further engaged in policy dialogue and project development on climate resilience. For instance, many business representatives find it burdensome to go through the accreditation process to participate in meetings of Local Disaster Risk Reduction and Management (DRRM) Councils. Such transaction costs may have inhibited their engagement in local-level DRRM planning and actions. Possible ways to further improving the institutional arrangements for enhancing climate resilience of MSMEs could be to:

- Identify potential areas where national-level government bodies with local presence (e.g. the Department of the Interior and Local Government, the Department of Agriculture, etc.) can enhance "vertical" co-ordination for strengthening MSMEs' climate resilience, building on existing institutional arrangements (e.g. the departments' own local offices) and guidance tools (e.g. guides on Comprehensive Development Plans and Comprehensive Land-Use Plans).

- Enhance the capacity of local DRRM officers and other local leaders in facilitating community participation in and deepening their understanding of the three policy agendas (MSME development, climate resilience and DRRM)): Relevant local institutions may include, but are not limited to, local business associations, co-operatives, civil society organisations, as well as Regional, Local and Barangay DRRM Committees.

- Where relevant, further engage the local chambers of commerce to complement the role of national-level institutions (e.g. the Philippine Chamber of Commerce and Industry and the Philippine Disaster Resilience Foundation) in order to better reach out to local MSMEs and provide them with training on business resilience through collaboration with LGUs and other local business networks.

- Review the accreditation processes for MSMEs to participate in Local DRRM Council meetings to facilitate exchange between the Council and MSMEs about climate hazards they are exposed to, their support needs, and broader business contexts that affect their vulnerability to climate change.

- Pursue deeper collaboration between academic networks and the private sector, which can offer a great potential to strengthen resilience of MSMEs to climate risks. Examples include universities and research institutes that participate in the Philippine Academic Society for Climate and Disaster Resilience.

- Help local MSMEs better organise themselves so that they can more effectively co-ordinate with (e.g.) LGUs and regional offices of the Philippines Atmospheric, Geophysical and Astronomical Services Administration (PAGASA) to access weather and climate data and information, and translate them into practical actions.

\section{Policy frameworks}

There is already a high-level conceptual convergence of policies across climate change adaptation, DRRM and MSME development in the Philippines, which is commendable (CCC, 2019 $9_{[54]}$; Government of the Philippines, 2010[77]; MSMED Council, 2018[72]). Progress on coherent implementation especially at the local level, however, varies markedly across policy areas and among different LGUs. Business continuity plans (BCP), for instance, have already been promoted through various public and private initiatives and are helping businesses to better prepare for disruptions after disasters. Yet, introducing regulatory incentives for businesses to consider long-term climate risks within their business operations is still at an early stage (OECD, 2020[39]). The challenges faced in policy implementation also include parallel strategies, action plans, tools and reporting mechanisms. Capacity constraints particularly at the local level are another major challenge, while LGU staff is often overloaded to work on a range of policy agendas with limited resources (CCC, 2019[54]; ADPC and DTI, 2016[76]). 
While this study examines the ensemble of MSMEs, the difference in size, sector and location among them may require support of the government and development co-operation to be tailored to the capacities and priorities of different groups of MSMEs. Further, promoting policy reforms in support of integrating informal micro and small businesses into the formal sector can enable them to benefit from formal support mechanisms for the resilience of MSMEs. Such support may include subsidies for certain technologies that aim at MSMEs' climate resilience, training on business continuity management, among others. Examples of potential entry points to consider MSMEs' climate resilience in policy frameworks could be to:

- Further strengthen capacities of LGUs to implement and enforce existing regulatory measures such as land-use management and environmental protection: They can serve as a basis to incentivise the private sector to engage in activities to enhance climate resilience, and allocate funding to such activities.

- Link the Green Jobs Act with the policies on MSME development and climate resilience, leveraging (e.g.) the collaboration between the Climate Change Commission, the Department of Labor and Employment and the International Labour Organization to identify the business opportunities for managing climate risks.

- Strengthen monitoring and evaluation to better understand how MSMEs are engaging in climate resilient actions and apply the learning to improve policies and programmes. For instance, there have been a number of training programmes on BCPs but many of them have not followed up on how many MSMEs actually set up a budget for and operationalise the BCPs.

\section{Data and information}

Both public- and private-sector institutions provide extensive climate- and weather-related data and information in the Philippines. There are already multiple examples of complementarity between private and public initiatives and platforms in this area. PAGASA is the national hydrological and meteorological agency of the country. WeatherPhilippines, a non-profit organisation founded by large company networks, had provided short-term weather forecast (Aboitiz, 2020[29]). Upon the recent closure of WeatherPhilippines, PAGASA is in charge of providing both short- to medium-term forecasts and longterm climate projections. The short-term forecast also helps to deploy humanitarian aid before the extreme climate event even strikes. The recently launched GeoRiskPH initiative can also set a model for the government, LGUs and academia to collaborate on data collection and information sharing. The collaboration could enable MSMEs to make better informed decisions related to managing climate and disaster risks (World Bank, 2020[70] $)$.

Separate from GeoRiskPH, the recently created Community-based Monitoring System (CBMS) would allow local communities to collect, process and validate locally specific data (PSA, 2019 ${ }_{[78]}$ ). The Philippine Statistics Authority leads CBMS implementation while the Department of Information and Communications Technology is tasked with developing data-sharing institutional arrangements, and the DILG with regularly disseminating outcomes of CBMS-related activities.

Despite the abovementioned progress, there remains limited availability of downscaled data on climate hazards, and information on vulnerability at the local level (CCC, 2019 $\left.{ }_{[54]}\right)$. Such data and information could help LGUs identify areas that are highly vulnerable and communities prone to climate and geophysical risks. More granular weather forecasts can help LGUs respond to extreme climate events and develop and improve relevant regulations over time (e.g. on land use management). Further, MSMEs, LGUs and insurance companies often lack historical data (e.g. past rainfalls, crop yields, economic losses to businesses). Even where such data has been collected, many companies, especially MSMEs, have difficulties in accessing the data or using it for generating information to adjust their business operations in order to manage climate and disaster risks. Apart from climate- and weather-related data, the availability of information on MSMEs themselves (e.g. their assets and operations) and on their vulnerabilities (e.g. location of the MSMEs and their adaptive capacities) remains limited. 
Development co-operation and the government can also further invest in medium- and long-term climate projections to help MSMEs better understand potential long-term impacts of climate change on their business opportunities and livelihoods in different regions. For example: How current crop yields may be affected, or which marketable crops and agriculture technologies are likely to be better suited to future climate conditions. Such analysis would also include market research to ensure that what can be grown has a market, or that new markets can be cultivated.

Climate-related data and information can be most effective when they complement the traditional knowledge and perceptions of MSMEs as well as information on their socio-economic circumstances. Not all MSMEs may be receptive to using climate-related information, if the information provided by the government or other institutions is not consistent with their own experience of past weather events, or when those MSMEs are not used to using such information. Notwithstanding, there are several proposed ways forward to enhancing weather and climate data and information in support of the resilience of MSMEs, which could be to:

- Improve the quality, quantity and accessibility of climate and weather data and information that are relevant to the decision making processes by MSME users: as both long-term climate projections and short to medium term forecasts (e.g. three to six months ahead for better disaster preparedness)

- Leverage on emerging initiatives such as the GeoRiskPH and LGU-level Community-based Monitoring System (CBMS) and other data-sharing institutional arrangements, to enhance the quality and accessibility of the data and information.

- Enhance information on MSMEs' operations, locations and assets as a basis for assessing their vulnerability and planning specific action, which can complement historical data on past weather events and future climate projections. This could happen through the collaboration between, for example, the Department of Trade and Industry, LGUs, Local and Barangay DRRM Committees, local business communities and civil society.

- Strengthen the capacity of local research institutions, and local business communities to generate local-level information which can be combined with information provided by the national-level institutions, academia, and large enterprises.

\section{Finance}

While MSMEs often use their own savings and support by family members and friends for recovery from disasters, the government has been funding a number of initiatives to support MSMEs to manage climate and disaster risks. The government has established a mixture of arrangements for financing climate and disaster risk management. They include: the National Disaster Risk Reduction and Management Fund, the Local Disaster Risk Reduction and Management Fund and the People's Survival Fund (OECD, $2020[39]$ ). These budgetary instruments support, for instance, the provision of social safety nets and marketbased instruments such as crop insurance, development of business continuity plans, and technical assistance for climate risk and vulnerability assessment. Some public funding is also channelled through state-owned financial institutions such as the Land Bank of the Philippines and the Small Business Corporation (SB Corp.) (SB Corp, n.d. [79]; LANDBANK, 2018[57]).

Challenges to scaling up finance for long-term measures for climate resilience span wide areas. They include limited awareness of climate and disaster risks among MSMEs, their lack of knowledge regarding financial solutions for these risks as well as low capacity in developing the competent funding proposals. More generally, limited public budget has hindered the scaling up of the government projects or capacity development activities beyond their pilot phase. The availability of public funding is likely to be further constrained by the need for the country's recovery effort from the health and economic impacts of the COVID-19 pandemic. The government-owned guarantee corporation, Philguarantee, could explore opportunities for credit enhancement for LGUs in order to catalyse private-sector investment in 
technologies and infrastructure in support of climate resilience (e.g. water supply and sanitation) (Climate Bonds Initiative, 2020[80]).

Possible ways forward to mobilising and scaling up finance to support MSMEs in building their resilience could be to:

- Identify, and prioritise public funding to, the common grounds between policies for MSMEs' climate resilience and other policy agendas, including economic recovery from the COVID-19 pandemic, improvement of agriculture-sector productivity, or the creation of green jobs:

- Integrate climate resilience considerations into the "mainstream" development projects of the vulnerable sectors (e.g. agriculture, tourism industry, coastal management, watershed management) to convert successful pilot activities into scaled-up projects that can engage a broader range of MSMEs.

- Introduce a MSME-related budget tagging system, aiming to make it easier for relevant government agencies that support MSMEs to identify financing gaps in MSME development and facilitate collaboration for bridging the gaps.

- Explore ways in which Philguarantee provide credit enhancement through LGUs to catalyse private-sector investment in technologies and infrastructure in support of climate resilience

- Enhance existing and potential partnerships between development co-operation providers and domestic financial institutions (e.g. public and commercial banks and insurance companies) to develop, test and disseminate financial products tailored to MSMEs' action on climate resilience, including affordable debt instruments and insurance products.

- Make use of potential mobile applications and online platforms to improve MSMEs' access to finance for climate resilience, while also building the capacity of traditional channels (e.g. 'sari-sari' stores) to reach micro businesses with little or no access to banks.

- Enhance enabling environments for further dissemination of (micro) insurance for MSMEs as part of comprehensive management of climate risks. Possible approaches include financial inclusion policies, legal requirements for certain MSMEs to purchase insurance products, development of open-source models, and data generation needed for the models, among others.

- Link climate risk considerations with the country's on-going efforts on financial education to build a knowledge base of MSMEs and households about credible financial solutions for enhancing climate resilience.

\section{Development co-operation}

Bilateral and multilateral providers of development co-operation play a crucial role in supporting the Philippines in enhancing climate resilience. More than $60 \%$ of bilateral and multilateral adaptation-related development finance targeted DRRM over the period between 2012 and 2018 (OECD, 2020[71]). The support provided takes different forms such as technical assistance (e.g. policy development, capacity building, and enhancement of data and information systems); pilots of new initiatives (e.g. development of parametric insurance); provision of grants and loans in case of disasters through disaster risk financing mechanisms (e.g. contingent credit lines and humanitarian aid); and lending for investment projects.

One challenge that remains in the Philippines is converting the outcomes of past and on-going capacity building and pilot activities into broader projects in order to support MSME resilience at scale (e.g. investment projects, scaled up training activities). Many capacity-building and pilot activities supported by development co-operation providers often have relatively short timeframes, which often makes it difficult for the effectiveness of the interventions to sustain (OECD, 2020[39]).

Development co-operation providers in the Philippines do communicate and co-ordinate with each other, and the National Economic Development Authority (NEDA) also serves as a focal point for development 
co-operation. Yet, it is often challenging to ensure coherence across development co-operation initiatives on the ground. For instance, different objectives and timeframes of development co-operation providers active within the same community often makes it challenging for LGUs to co-ordinate those support activities. While the Climate Change Commission had organised formal donor co-ordination meetings in the past, it hosts rather informal, ad-hoc meetings at the time of writing. Although such ad-hoc meetings are useful for the co-ordination of government and development co-operation providers, it could also be worth reviving formal donor meetings. In doing so, the scope of the meetings could be expanded to include issues around climate resilience of MSMEs, for example through the participation of appropriate institutions such as MSME Resilience Core Group, the National Resilience Council, the Climate Change Commission, NEDA, among others.

Finally, initiatives by business networks in the Philippines recognise climate risks in their efforts to enhance MSMEs' resilience to disasters. However, many of the initiatives are mainly focused on post-disaster business continuity management so far. Development co-operation is supporting MSME climate resilience and can further support with the incorporation of long-term climate risk management into not only business continuity plans but also a broader range of business operations of MSMEs. For example, development co-operation providers could use their expertise and experience in (e.g.) conducting climate risk and vulnerability assessments, enhancing climate data and information systems and developing MSMEspecific financial products within and outside the Philippines. Possible areas where development cooperation can further support the resilience of MSMEs to climate risks could be to:

- Ensure that development co-operation efforts are aligned with local-level processes, priorities, and political commitments related to the country's climate-related and broader development objectives.

- Consider reviving the Climate Change Commission's regular donor co-ordination meetings on climate change adaptation and DRRM, and possibly also engage those who work on MSME sector development in such meetings.

- Help LGUs and local business communities to build capacity in collaboration with the academia and private-sector networks. Such support can build capacity of MSMEs and LGUs to conduct climate risk assessment and to better access the domestic funding that is available but largely unused (e.g. the People's Survival Fund, lending programmes offered by the Land Bank of the Philippines and SB Corp).

\subsection{Approaches in Senegal: Findings and ways forward 6}

Senegal is vulnerable to several natural hazards, particularly coastal erosion, droughts, floods, and locust invasions (Crick et al., 2018[81]). Climate change is exacerbating these hazardous risks, especially for micro, small and medium-sized enterprises (MSMEs). MSMEs represent up to $90 \%$ of Senegalese companies (OECD, 2017 [82] ) and contribute towards 30\% of the country's gross domestic product, as well as employ almost $60 \%$ of the economically active population (Crick et al., 2016 ${ }_{[83]}$ ). Therefore, it is extremely importance to strengthen the resilience of MSMEs against climate-related risks to ensure that Senegal is able to pursue a sustainable development pathway. Despite a key role in the country's socioeconomic fabric, the adaptive capacity of MSMEs to climate change risks is low. This is particularly true for MSMEs that are small, that are not organised, that operate in remote areas or that are led by women (Diop et al., 2018[84]).

It is unclear how MSMEs are faring in the field of climate resilience. While there are several ministries or agencies that support the development of MSMEs, no governmental entity is yet mandated to monitor the climate resilience of MSMEs. Research to date shows that most MSMEs are aware of climate risks but

\footnotetext{
${ }^{6}$ A full report of the case study is available on: https://www.oecd.org/development/climate-resilience/
} 
MSMEs have not taken actions yet, due to various constraints. Enhancing the resilience of MSMEs is slowly being integrated into the country's private sector development, yet a clear business case to accelerate action is still missing. This suggests the importance of further integration of climate considerations into the guiding national development framework.

Developing a national narrative that presents climate resilience as an area where MSMEs can produce economic returns, as the country recently achieved for renewable energy investments against power shortages, would also be beneficial. Other parts of the Senegalese private sector could also embrace climate resilience through Corporate Social Responsibility, particularly multinational companies, commercial banks with climate-specific credit lines for MSMEs, or the nascent start-up sector with capacity building tools for climate resilience. Larger companies could also be motivated to ensure that their value chains, including the MSMEs that are part of it, are resilient. The current COVID-19 crisis provides Senegal with an opportunity to integrate MSME resilience issues into the crisis recovery package, although early evidence suggests that MSMEs may not be well represented in the bodies designing the recovery policies.

This subsection summarises findings of a case study that examines how the Senegalese national government and development co-operation providers collaborate with the private sector to strengthen the resilience of MSMEs to manage negative impacts of climate change and variability. This study considers the institutional arrangements, policy frameworks, data and information, as well as financial mechanisms that support MSMEs in the face of short and long-term climate risks in Senegal.

\section{Institutional arrangements}

Despite enjoying greater political stability and better governance than other countries in the region (OECD, $2017_{[82]}$ ), both general and specific governance challenges remain to strengthen climate resilience, notably its integration into the activities of MSMEs in Senegal. Among the general challenges are difficulties for the national government to lead reforms, enforce legislation and execute the budget, as well as leadership turn-over in ministries and agencies.

Specific challenges include limited participation of the private sector, notably of MSMEs in the National Committee on Climate Change (COMNACC), the governmental institution that could support MSMEs on climate resilience issues. The sub-national institutional setup, including the Regional Climate Change Committees (COMRECCs) that ought to inform the work of the COMNACC, is unable to deliver support to MSMEs due to capacity and financial constraints. As a result of prolific governmental entities and institutions with mandates to support different aspects of MSME development, which often operate in parallel without effective co-ordination, a clear responsibility for helping MSMEs build their climate resilience is lost. The government of Senegal, with support of providers of development co-operation, could:

- Implement the recommendations from a recent COMNACC assessment report to ensure the Committee becomes an autonomous, financially independent and an authoritative source on climate-related issues in Senegal. The reform needs to extend to the local level and ensure that a regular dialogue is established with the private sector, notably MSMEs.

- Support the on-going plans to reform the current institutional arrangements for MSMEs to create a one-stop-shop that would facilitate their access to financial and technical support.

- Build the capacity of the national and local institutions that support MSMEs in delivering climate and weather information and training programmes. In addition, they could share available climate resilience solutions and measures, facilitate access to domestic and international climate funding, as well as assess and develop business plans for MSMEs that incorporate climate-related risks.

- Develop a platform where MSMEs and COMRECCs can exchange more information on good practices, factors for success (e.g. in some of the operational COMRECCs why and how they achieved results and engaged the private sector) and lessons learnt. 


\section{Policy frameworks}

The overarching national development strategy of Senegal, the Plan Sénégal Émergent (PSE) for the period 2014-2023 already highlights the importance of climate change issues, providing high-level visibility to this topic (Government of Senegal, 2019[85]). However, concrete policy proposals in the PSE implementation plans, the Plans d'Actions Prioritaires (PAP), make a limited reference to climate resilience issues (Government of Senegal, 2019[85]). Beyond the PSE, coherence and interaction between different sectoral and thematic policies remain limited. The private sector has participated in the PSE and PAP development, as well as in other climate-related policies such as the Environmental Code and the National Adaptation Plan process. However, policy implementation and enforcement often do away with MSMEs.

Climate change adaptation and disaster risk reduction-related frameworks, including the National Adaptation Programme of Action, the Nationally Determined Contributions and the National Adaptation Plan (NAP) take a sectoral approach. Development co-operation providers have been supporting bottomup NAP processes. While the NAP takes into account the PSE, neither the PSE nor the PAP 2019-23 take the NAP into account, showing that resilience-related frameworks are not yet fully integrated into national frameworks.

Several sector-level frameworks and policy tools are being updated and could incorporate climate resilience considerations. Other frameworks such as those promoting youth employment, women's economic empowerment, or food security could also be fleshed out in ways that promote MSME resilience and connect with existing policies (e.g. the Stratégie Nationale pour l'Egalité et l'Equité de Genre or the Stratégie Nationale de Sécurité Alimentaire et de Résilience). Against this background, the government of Senegal, with support of providers of development co-operation, could:

- Update national frameworks (i.e. PSE and PAP) and sectoral frameworks (e.g. youth employment, women's economic empowerment and food security) to more explicitly integrate climate resilience narratives and frameworks, as well as reflect the importance of MSME resilience for the sustainable development of Senegal.

- Ensure that legal frameworks and policies are implemented, as well as enforced, monitored and evaluated - as the policy cycle appears to function best up until the point of implementation. Providers could support Senegal in doing so by ensuring that funding instruments are devised beyond capacity building and technical assistance to draw up these frameworks and policies.

\section{Data and information}

Weather and climate data and information are improving in Senegal but remain insufficient for MSMEs in terms of granularity, regional breadth, accessibility and affordability. The data and information tend to be delivered during the rainy season, but farmers would prefer to receive such information throughout the year. The National Agency for Civil Aviation and Meteorology (ANACIM), the national meteorological office, has been riddled by frequent management changes, which delayed the implementation of several projects on climate and weather data and information. Moreover, placed within the Ministry of Tourism and Air Transport, ANACIM only became gradually aware of climate risks, notably through tourism. With several local languages in Senegal, the current practice of disseminating the information only in French may not be adequate to reach all MSMEs.

There is nevertheless several encouraging changes emerging. ANACIM through its National Framework for Climate Services, developed in 2017, has started providing targeted information and data directly to MSMEs, often joining forces with the governmental institutions that support MSMEs. Development cooperation providers have often driven changes in policy development, in collaboration with the government. For example, ANACIM worked with USAID to develop the National Framework, and with Canada and others to deploy meteorological stations in a number of regions, dramatically improving the information available. ANACIM also presides an Inter-ministerial Council on Climate services that helps participating 
ministries integrate climate information and predictions into planning and policy frameworks (USAID, 2017[86] $)\left(\right.$ WMO, 2018 $\left.{ }_{[48]}\right)$. To continue improving climate data and information for the benefit of MSMEs, the government of Senegal, with support of providers of development co-operation, could:

- Develop a nationwide narrative to convince MSMEs of the benefits of using weather and climate data and information, going beyond traditions and personal experience, to inform adaptation and resilience actions.

- Engage private sector telecommunications operators, such as Orange or Free, in a dialogue with ANACIM and other public authorities to deliver affordable, targeted and accessible climate information to MSMEs.

- Explore ways for the government to promote corporate social responsibility programmes that align with climate information needs, such as financially supporting the ANACIM, organising scientific exchanges and other activities at the local level, with participation by the COMNACC.

- Continue expanding the meteorological station network, with support from providers of development co-operation. They could also start allocating resources for this endeavour, prioritising the maintenance of existing stations, and continue delivering training to maintain and operate this equipment, as well as on recent climate-related scientific development to relevant stakeholders.

\section{Finance}

Public financial support schemes for MSMEs have burgeoned with the PSE in Senegal - but these are not incorporating climate resilience issues explicitly. The same can be said for financial products offered by most commercial banks, with the exception of the Banque Agricole that has recently changed its operating model to integrate climate resilience. In general, access of MSMEs, especially informal ones, to commercial loans remains a challenge whether the loans are for action on climate resilience or not. Yet, the Banque Agricole has made agricultural insurance obligatory for a client to sign a loan. By doing so, the Senegalese insurance sector is delivering promising results on resilience, even if the business model may not be sustainable. Despite reticence from farmers and fisherfolks, limited awareness and support from public authorities, the National Agricultural Insurance Company of Senegal (CNAAS) managed to cover $10 \%$ of the farmers in the country in a few years. According to stakeholders, the CNAAS is already breaking even by providing widespread insurance in the Senegal River Valley, thus enabling economic activities and resilience to bloom there. New insurance tools are being piloted in other areas (e.g. fisheries sector; flexible risk transfer options such as insurance-for-assets programmes) and across regions, including through the use of satellite-based insurance indexes. New domestic actors are also entering this space again providing opportunities to foster financial resilience of farmers against disasters; and new ways to raise awareness are being piloted (e.g. the CNAAS uses the regional network of the Banque Agricole; radios promote insurance through an 'insurance day'; awareness is done in several local languages).

Other forms of financing also need to be explored, notably remittances, which could be harnessed by providers of development co-operation to support resilience through their interventions (e.g. by promoting lower remittance rates or by co-ordinating and targeting activities according to remittance flows). In addition, accessing international climate finance can also be a difficult endeavour for Senegalese stakeholders, and would require a partnership across institutions, including the Ministries of Finance and the Environment. To further mobilise finance for climate resilience of MSMEs, the government of Senegal, with support from providers of development co-operation, could:

- Explore ways in which the three financial bodies created under the PSE can incorporate climate resilience considerations into their business models and strategies by reinforcing the mandate and funding model for these institutions to support MSMEs (for example, reorganisation of technical processes or the development of new products). 
- Work with the agriculture and livestock sectors to ensure that index-based insurance takes off, and continue exploring options for the fisheries sector.

- Work with insurance companies, such as the CNAAS, so that they can continue adapting their products to MSMEs' context, and promote culturally-sensitive dissemination and perceptionchanging campaigns. The CNAAS could become a regional leader if it were able to develop a more sustainable business model for its insurance products.

\section{The role of providers of development co-operation}

Providers of development co-operation have been investing in climate resilience for a long time in Senegal. Over 2012-18, bilateral and multilateral development cooperation providers committed USD 43 million on official development assistance on average per year to climate change adaptation in the country, according to OECD DAC statistics (OECD, 2020 [71]). Development co-operation providers have often driven action on climate resilience in Senegal through supporting the development of the institutional setting, policy frameworks, the country's financial system, as well as weather and climate data and information. Notwithstanding this comprehensive support, the stakeholder interviews revealed that a greater collaboration between providers, MSMEs and the government in Senegal could be achieved. Providers could improve their activities through:

- Directly engaging with MSMEs in efforts to build their climate resilience in co-ordination with relevant governmental entities, despite the perceived risk in investing directly in operations with MSMEs (e.g. higher default risks).

- Working with domestic commercial banks, whose clients are mainly MSMEs, and learning from ongoing projects and experiences in this area, and seeking formulas to support informal MSMEs.

- Enhancing the policy coherence within providers' own project portfolio to ensure that their development co-operation in industrial and trade policies and climate resilience issues are aligned across the board.

- Promoting digitalisation and digital technologies to engage the youth, who are more receptive to changes, and who could lead the way in climate resilience and climate change issues more generally, for example, by engaging with burgeoning Senegalese fintech start-ups.

- Providing financial and technical support to the green pillar of the second implementation plan (2019-2023) of the PSE, as well as mainstream climate resilience considerations across their own activities.

Despite its size, Senegal is an influential regional partner, notably for Western Africa. Other countries in the region often copy successful projects and programmes developed in Senegal. Member countries of the Economic Community of West African States, in particular, hold regular meetings on climate resilience. In these, the lessons learnt, good practices and the successful experiences made in Senegal could be replicated at sub-regional level or brought to scale when engaging one or more countries there. 


\section{References}

Aboitiz (2020), Aboitiz donates weather technology assets to government, https://aboitiz.com/aboitiz-donates-weather-technology-assets-to-government/ (accessed on 11 September 2020).

ADB (2017), Assessment of microinsurance as emerging microfinance for the poor: The case of the Philippines, Asian Development Bank (ADB), Mandaluyong City, https://www.adb.org/sites/default/files/publication/226171/assessment-microinsuranceservice.pdf.

ADPC and DTI (2016), Roadmap for Strengthening the Disaster-Resilience of Micro, Small and Medium Enterprises, The Asian Disaster Preparedness Center (ADPC), and the Department of Trade and Industry (DTI), https://www.dti.gov.ph/negosyo/msme-disaster-resiliencyl.

Africa Adaptation Initiative (2020), Integrated Responses to Building Climate and Pandemic Resilience (Draft communiqué), Africa Adaptation Initiative, https://www.africaadaptationinitiative.org/assets/DRAFT\%20COMMUNIQUE COVID\%20\&\% 20ADAPTATION\%20in\%20AFRICA SN140520.pdf.

Butler, J. et al. (2015), "Integrating Top-Down and Bottom-Up Adaptation Planning to Build Adaptive Capacity: A Structured Learning Approach", Coastal Management, Vol. 43/4, pp. 346-364, http://dx.doi.org/10.1080/08920753.2015.1046802.

CCC (2019), Executive Brief: The Philippine National Climate Change Action Plan, Monitoring and Evaluation Report 2011-2016., Climate Change Commission (CCC), Manila, https://climate.gov.ph/files/The\%20Philippine\%20NCCAP\%20M\%26E\%20Executive\%20Brief $\% 20 \% 5$ Bv2\%5D.pdf.

Christian Aid (n.d.), Christian Aid in the Philippines, Christian Aid, https://www.christianaid.org.uk/our-work/where-we-work/philippines (accessed on 26 April 2021).

CICA (2019), White Book: For an agriculture more resilient and better protected against climate hazards, Confédération Internationale du Crédit Agricole (CICA), http://www.cica.ws/conferences (accessed on 12 August 2020).

CIG (2019), Industriales disertan acerca del cambio climático en el Foro de Ambiente - FACIG , Cámara de Industria de Guatemala, https://cig.industriaguate.com/2019/07/17/industrialesdisertan-acerca-del-cambio-climatico-en-el-foro-de-ambiente-facig/ (accessed on 19 October 2020).

Climate Bonds Initiative (2020), Philippines Green Infrastructure Investment Opportunities Report, https://www.climatebonds.net/system/tdf/reports/cbi giio phillipines 20 06a final.pdf?file=1\& type=node\&id=54881.

Crawford, A. and C. Church (2019), Engaging the Private Sector in National Adaptation Planning Processes, International Institute for Sustainable Developme (IISD), http://www.napglobalnetwork.org (accessed on 30 January 2020). 
Crawford, A., C. Church and C. Ledwell (2020), Toolkit for Engaging the Private Sector in National AdaptationPlans (NAPs): Supplement to the UNFCCC Technical Guidelines for the NAP process, NAP Global Network \& United Nations Framework Convention on Climate Change Adaptation Committee. International Institute for Sustainable Developme, http://www.napglobalnetwork.org/.

Crick, F. et al. (2016), Enabling private sector adaptation in developing countries and their semiarid regions - case studies of Senegal and Kenya, Grantham Research Institute on Climate Change and the Environment, http://www.lse.ac.uk/Granthamlnstitute/wpcontent/uploads/2016/12/Working-Paper-258-Crick-et-al.pdf.

Crick, F. et al. (2018), "How do African SMEs respond to climate risks? Evidence from Kenya and Senegal", World Development, 108, 157-168., https://doi.org/10.1016/i.worlddev.2018.03.015.

Crick, F. et al. (2018), "How do African SMEs respond to climate risks? Evidence from Kenya and Senegal", World Development, Vol. 108, pp. 157-168, http://dx.doi.org/10.1016/j.worlddev.2018.03.015.

Crishna Morgado, N. and B. Lasfargues (2017), Engaging the Private Sector for Green Growth and Climate Action: An Overview of Development Co-Operation Efforts, OECD Development Co-operation Working Papers, No. 34, OECD Publishing, Paris, https://doi.org/10.1787/85b52daf-en.

Dazé, A., H. Price-Kelly and N. Rass (2016), Vertical Integration in National Adaptation Plan (NAP) Processes: A guidance note for linking national and sub-national adaptation processes, International Institute for Sustainable Development (IISD), http://www.napglobalnetwork.org (accessed on 18 February 2020).

Diop, M. et al. (2018), Genre, Vulnérabilité et Adaptation: Cas des Femmes Entrepreneurs en Zones Semi-Arides du Sénégal, IED Afrique, http://www.iedafrique.org/lMG/pdf/project 4 gender final.pdf.

Dornelles, A. et al. (2020), "Towards a bridging concept for undesirable resilience in socialecological systems", Global Sustainability, Vol. 3/e20, pp. 1-12, http://dx.doi.org/10.1017/sus.2020.15.

Dougherty-Choux, L. et al. (2015), Adapting from the Ground Up: Enabling Small Businesses in Developing Countries to Adapt to Climate Change, World Resources Institute, https://www.wri.org/publication/adapting-from-the-ground-up.

Ford, J. et al. (2018), "Vulnerability and its discontents: the past, present, and future of climate change vulnerability research", Climatic Change (2018) 151:189-203, https://doi.org/10.1007/s10584-018-2304-1.

GCA (2020), Call to Action for a Climate-Resilient Recovery from COVID-19, The Global Commission on Adaptation (GCA), https://cdn.gca.org/assets/202007/Global Commission Adapation COVID Resilience Statement.pdf.

GCF (2019), Strategic Frameworks support for the Philippines through IFC, Green Climate Fund, Songdo, https://www.greenclimate.fund/document/strategic-frameworks-support-philippinesthrough-ifc. 
GIZ (2020), Mainstreaming Gender within Local Government Climate and Disaster Risk Assessments A Review of Methodology and Practice in the Philippines, Deutsche Gesellschaft Für Internationale Zusammenarbeit (GIZ), https://2eac3a3b-5e23-43c7-b33cf17ad8fd3011.filesusr.com/ugd/558f8a fcfc4f812f8f4659925e8d3b7dbdef3b.pdf.

GIZ (n.d.), CLIMATE EXPERT: Home, Deutsche Gesellschaft Für Internationale Zusammenarbeit (GIZ) gmbh, Eschborn/Bonn, https://www.climate-expert.org/en/home/ (accessed on 26 April 2021).

Global Affairs Canada (2019), Evaluation of Natural Disaster Reconstruction Assistance in the Philippines 2013-14 to 2018-19, http://www.oecd.org/derec/canada/canada-natural-disasterphilippines2012-14-2018-19.pdf.

Government of Ghana (2019), Ghana's Private Sector Engagement Strategy for the National Adaptation Plan. Government of Ghana, Environmental Protection Agency, Government of Ghana, https://napglobalnetwork.org/resource/ghana-private-sector-engagement-strategy-forthe-nap/.

Government of Philippines (2018), SB Corp strengthens rehab fund for SMEs thru a hammer | Board of Investments, Philippines Board of Investments (BOI), https://boi.gov.ph/sb-corpstrengthens-rehab-fund-for-smes-thru-a-hammer/ (accessed on 24 May 2020).

Government of Saint Lucia (2020), Saint Lucia's Private Sector Engagement Strategy Under the National Adaptation Planning Process, Government of Saint Lucia, https://napglobalnetwork.org/resource/saint-lucia-private-sector-engagement-strategy/.

Government of Senegal (2019), Plan Sénégal Émergent: Plan d'Actions Prioritaires (2019-2023), Government of Senegal, https://www.sentresor.org/app/uploads/pap2 pse.pdf.

Government of the Philippines (2010), R.A. No. 10121, Philippine Disaster Risk Reduction and Management Act of 2010, Government of the Philippines, https://www.lawphil.net/statutes/repacts/ra2010/ra 10121 2010.html (accessed on 25 July 2019).

Government of the Philippines (n.d.), Agricultural Credit Policy Council (ACPC), Government of the Philippines, http://acpc.gov.ph/sure/ (accessed on 25 May 2020).

Government of Viet Nam (2020), Private Sector Engagement in National Adaptation Plan Development and Implementation in Vietnam, Department of Climate Change, Government of Viet Nam, https://napglobalnetwork.org/resource/private-sector-engagement-in-nationaladaptation-plan-development-and-implementation-in-vietnam/.

Hallegatte, S. et al. (2016), Unbreakable: Building the Resilience of the Poor in the Face of Natural Disasters, The World Bank, http://dx.doi.org/10.1596/978-1-4648-1003-9.

HLURB (n.d.), Climate and Disaster Risk Assessment (CDRA) Overview, Housing and Land Use Regulatory Board (HLURB), Manila, https://designingresilience.ph/wp-content/uploads/CDRAOverview.pdf (accessed on 26 April 2021).

ICC (2020), Ciclo de Webinar: Gestión del Riesgo de Desastres para la Resiliencia Empresarial, Institute for Climate Change Research (ICC), http://, https://icc.org.gt/es/webinar-gestion-delriesgo-de-desastres-para-la-resiliencia-empresarial/. 
IDB Invest (2020), IDB Invest promotes access to financing for MSME through Genesis in

Guatemala, Inter-American Investment Corporation (IDB Invest),

https://www.idbinvest.org/en/news-media/idb-invest-promotes-access-financing-msmethrough-genesis-guatemala.

ILO (2019), The Power of Small: Unlocking the Potential of SMEs, International Labour

Organization, Geneva, https://www.ilo.org/infostories/en-

GB/Stories/Employment/SMEs\#engines (accessed on 12 August 2020).

IPCC (2019), "Annex I: Glossary", in van Diemen, R. (ed.), Climate Change and Land: an IPCC special report on climate change, desertification, land degradation, sustainable land management, food security, and greenhouse gas fluxes in terrestrial ecosystems, https://www.ipcc.ch/site/assets/uploads/sites/4/2019/11/11 Annex-I-Glossary.pdf (accessed on 6 February 2020).

IPCC (2018), Annex I: Glossary [Matthews, J.B.R. (ed.)]. In: Global Warming of $1.5^{\circ} \mathrm{C}$. An IPCC Special Report on the impacts of global warming of $1.5^{\circ} \mathrm{C}$ above pre-industrial levels and related global greenhouse gas emission pathways, in the context of strengthening the global response to the threat of climate change, sustainable development, and efforts to eradicate poverty, https://www.ipcc.ch/sr15/chapter/glossary/ (accessed on 21 January 2020).

iPrepare Business facility (2017), Strengthening Disaster and Climate Resilience of Small \& Medium Enterprises in Asia: Philippines - Enabling Environment \& Opportunities, Asian Disaster Preparedness Center (ADPC), Bangkok, https://app.adpc.net/sites/default/files/public/publications/attachments/3\%20IP CR philippine s.pdf (accessed on 25 February 2020).

LANDBANK (2018), , The Land Bank of the Philippines (LANDBANK), Manila, https://www.landbank.com/images/inner template/1578986267 LANDBANK\%202018\%20SR web\%20copy\%20011020 compressed.pdf.

LIFE-AR (2019), Delivering our climate-resilient future: lessons from a global evidence review, The LDC Initiative for Effective Adaptation and Resilience (LIFE-AR), http://www.ldcclimate.org/wp-content/uploads/2019/09/web LDCevidencereview.pdf.

MARN (2016), Segunda Comunicación Nacional sobre Cambio Climático Guatemala, MARN, https://unfccc.int/sites/default/files/resource/gtmnc2.pdf.

MARN (2013), Ley Marco para Regular la Reducción de la Vulnerabilidad, la Adaptación Obligatoria ante los Efectos del Cambio Climático y la Mitigación de Gases de Efecto Invernadero (Decreto 7-2013), MARN, https://www.marn.gob.gt/Multimedios/2682.pdf.

Mavrodieva et al. (2019), "Governmental Incentivization for SMEs' Engagement in Disaster Resilience in Southeast Asia", International Journal of Disaster Risk Management, Vol. 1, No. 1, pp. 32-50, https://doi.org/10.18485/ijdrm.2019.1.1.2.

MCII and GIZ (2019), Roadmap for Integrated Climate Risk Management: Drought Risk in Ghana's Agricultural Sector, United Nations University Institute for Environment and Human Security (UNU-EHS) / Deutsche Gesellschaft für Internationale Zusammenarbeit (GI, https://reliefweb.int/sites/reliefweb.int/files/resources/reach lby situation overview immi jun e 2019 0.pdf. 
MiCRO (2017), Our first index insurance product is up and running in Guatemala - MiCRO Insurance MiCRO, Microinsurance Catastrophe Risk Organisation, https://www.microrisk.org/first-index-insurance-product-running-guatemala/ (accessed on 22 September 2020).

MINECO (2015), Sistema Nacional de Información MIPYME de Guatemala, MINECO, http://www.mineco.gob.gt/sites/default/files/Comunicacion\%20Social/sistema nacional de in formacion mipyme guatemala ano base 2015.pdf.

MSME Resilience Core Group (2020), MSME Guide to Disaster Resilience, https://dtiwebfiles.s3-ap-southeast-1.amazonaws.com/elibrary/Growing+a+Business/MSME+Guidebook First+Edition+April+2020.pdf.

MSMED Council (2018), Micro, Small and Medium Enterprise Development Plan 2017-2022, Department of Trade and Industry , Manila, http://www.philexport.ph/c/document library/get file?uuid=e77ef7f0-d768-422f-83303090c0ce97bd\&groupld=127524.

NAP Global Network (n.d.), Key themes, http://napglobalnetwork.org/themes/ (accessed on 28 August 2020).

Nielsen (2014), Sari-sari stores: Maximizing distribution opportunities - Nielsen, Nielsen, https://www.nielsen.com/ph/en/insights/article/2014/sari-sari-stores-maximizing-distributionopportunities/ (accessed on 25 March 2020).

NRC (2018), For resilience: NRC partners attend first phase of climate and disaster risk assessment course, National Resilience Council (NRC), https://resiliencecouncil.ph/forresilience-nrc-partners-attend-first-phase-of-climate-and-disaster-risk-assessment-course/ (accessed on 12 March 2020).

OECD (2021), Strengthening Climate Resilience: Guidance for Governments and Development Co-operation, OECD Publishing, Paris, https://doi.org/10.1787/4b08b7be-en.

OECD (2020), Climate Change: OECD DAC External Development Finance Statistics, OECD Development Assistance Committee, http://www.oecd.org/dac/financing-sustainabledevelopment/development-finance-topics/climate-change.htm (accessed on 26 April 2021).

OECD (2020), Common Ground Between the Paris Agreement and the Sendai Framework : Climate Change Adaptation and Disaster Risk Reduction, OECD Publishing, Paris, https://dx.doi.org/10.1787/3edc8d09-en.

OECD (2020), COVID-19 GLOBAL PANDEMIC: Joint Statement by the Development Assistance Committee (DAC) of the OECD, https://www.oecd.org/dac/development-assistancecommittee/DAC-Joint-Statement-COVID-19.pdf.

OECD (2020), The impact of the coronavirus (COVID-19) crisis on development finance, OECD, http://www.oecd.org/coronavirus/policy-responses/the-impact-of-the-coronavirus-covid-19crisis-on-development-finance-9de00b3b/.

OECD (2019), Aligning Development Co-operation and Climate Action: The Only Way Forward, The Development Dimension, OECD Publishing, Paris, https://dx.doi.org/10.1787/5099ad91en. 
OECD (2018), Development Co-operation Report 2018: Joining Forces to Leave No One

Behind, OECD Publishing, Paris, https://dx.doi.org/10.1787/dcr-2018-en.

OECD (2017), Examen multidimensionnel du Sénégal, Volume 1. Évaluation initiale, OECD, http://www.oecd.org/fr/pays/senegal/examen-multidimensionnel-du-senegal-9789264273092fr.htm.

OECD (2017), Getting Governments Organised to Deliver on the Sustainable Development Goals: High Level Political Forum, OECD Publishing, http://www.oecd.org/gov/SDGsSummary-Report-WEB.pdf (accessed on 17 June 2020).

OECD (2009), Integrating Climate Change Adaptation into Development Co-operation: Policy Guidance, OECD Publishing, Paris, https://dx.doi.org/10.1787/9789264054950-en.

OECD (2005), Glossary of Statistical Terms: SMALL AND MEDIUM-SIZED ENTERPRISES (SMES), https://stats.oecd.org/glossary/detail.asp?ID=3123 (accessed on 3 May 2021).

OECD (2003), Glossary of Statistical Terms: Economic Instruments (Environmental Protection Policy), https://stats.oecd.org/glossary/detail.asp?ID=723\#: :text=Economic\%20instruments\%20are\% 20fiscal\%20and,consumption\%20through\%20full\%2Dcost\%20pricing.

Phillips et al. (2020), "Compound climate risks in the COVID-19 pandemic.", Nature Climate Change, https://doi.org/10.1038/s41558-020-0804-2.

PSA (2019), Community-Based Monitoring System Act, Philippine Statistics Authority (PSA), https://psa.gov.ph/content/community-based-monitoring-system-act.

SB Corp (n.d.), SB Corp celebrates 27 years of nation-building through MSME development | Small Business Corporation, Small Business Corporation, https://www.sbgfc.org.ph/news/sbcorp-celebrates-27-years-nation-building-through-msme-development (accessed on 24 May 2020).

Schaer, C. and N. Kuruppu (2018), Private-sector action in adaptation: Perspectives on the role of micro, small and medium size enterprises., UNEP DTU Partnership, https://orbit.dtu.dk/ws/files/162053774/MSME Adaptation updated WEB.pdf (accessed on 1 August 2019).

Sereenonchai, S. and N. Arunrat (2019), “Fishers' Decisions to Adopt Adaptation Strategies and Expectations for Their Children to Pursue the Same Profession in Chumphon Province, Thailand", Climate 2019, http://dx.doi.org/10.3390/cli7020034.

Street, R. (2019), "How could climate services support disaster risk reduction in the 21st century", International Journal of Disaster Risk Reduction, Vol. 24/March, pp. 28-33, http://dx.doi.org/10.1016/j.ijdrr.2018.12.001.

UN Environment (2018), Adaptation Gap Report 2018, United Nations Environment Programme, Nairobi, Kenya, https://www.unenvironment.org/resources/adaptation-gap-report (accessed on 1 August 2019).

UNDP (n.d.), Engaging the Private Sector, https://www.adaptation-undp.org/privatesector/ (accessed on 9 August 2020). 
UNDP and PBE (2017), Transformational Business | UNDP in Philippines, UNDP Philippines, Philippine Business for the Environment (PBE), Manila, https://www.ph.undp.org/content/philippines/en/home/library/privatesectorsustainabledevt/tran sformationalbusiness.html (accessed on 9 March 2020).

UNDRR (n.d.), Quick Risk Estimation (QRE) Tool, United Nations Office for Disaster Risk Reduction (UNDRR), Bonn, https://www.businessgre.net/ (accessed on 26 April 2021).

UNEP DTU (2018), Building Business Climate Resilient - UNEP DTU Partnership, UNEP DTU Partnership, Copenhagen, https://unepdtu.org/project/innovative-decision-support-tools-forbuilding-business-resilience-to-climate-change-in-sri-lanka/ (accessed on 26 April 2021).

UNESCO (2017), Local Knowledge, Global Goals, The United Nations Educational, Scientific and Cultural Organization (UNESCO), http://www.unesco.org/new/fileadmin/MULTIMEDIA/HQ/SC/pdf/LLK ex publication E.pdf.

USAID (2017), Climate change risk profile: Guatemala, USAID, https://www.climatelinks.org/resources/climate-risk-profileguatemala\#: : :text=In\%20Guatemala\%2C\%20climate\%20change\%20poses, \%2Dand\%2Dbur n\%20agricultural\%20practices. (accessed on 26 April 2021).

USAID (2017), Climate Change Risk Profile: Senegal, USAID, https://www.climatelinks.org/sites/default/files/asset/document/2017 USAID\%20ATLAS Clim ate\%20Change $\% 20$ Risk\%20Profile\%20-\%20Senegal.pdf (accessed on 26 April 2021).

USAID (2017), USAID and partners celebrate completion of P76 million agri project in Bicol, https://www.usaid.gov/philippines/press-releases/jul-18-2017-usaid-and-partners-celebratecompletion-p76-million-agri (accessed on 22 April 2021).

Vivid Economics (2020), Greenness of Stimulus Index, Vivid Economics Ltd, https://cdn.gca.org/assets/202007/Global Commission Adapation COVID Resilience Statement.pdf.

Weaver, C. et al. (2017), "Reframing climate change assessments around risk: recommendations for the US National Climate Assessment", Environmental Research Letters, Vol. 12/9, http://dx.doi.org/10.1088/1748-9326/aa846a.

WFP (2020), WFP Guatemala: Country Brief, World Food Programme, Rome, https://reliefweb.int/sites/reliefweb.int/files/resources/WFP-0000120300.pdf (accessed on 26 April 2021).

WMO (2018), Sowing the Seeds for Climate Action in Senegal, World Meteorological Organization, https://public.wmo.int/en/resources/meteoworld/sowing-seeds-climate-actionsenegal (accessed on 7 June 2020).

World Bank (2020), Public Sector Database, World Bank Group, Washington D.C., https://data.worldbank.org/topic/public-sector (accessed on 26 April 2021).

World Bank (2014), SME Development in Guatemala: Let 10,000 Firms Bloom, World Bank Group, Washington D.C., http://documents1.worldbank.org/curated/en/718641468283161938/pdf/542420v10ESW0G0e 0only0900BOX358360B.pdf (accessed on 26 April 2021). 
58 